\title{
The Distribution of Enkephalinlike Immunoreactivity in the Telencephalon of the Adult and Developing Domestic Chicken
}

\author{
ANTON REINER, BRIAN M. DAVIS, NICHOLAS C. BRECHA, AND \\ HARVEY J. KARTEN
}

Department of Anatomy and Cell Biology, University of Michigan, Ann Arbor, 48109 (A.R.), Department of Neurobiology and Behavior, SUNY at Stony Brook, Stony Brook, New York,(B.M.D., H.J.K.), and CURE, Wadsworth VA Center, Los Angeles, (N.C.B.)

\begin{abstract}
Immunohistochemical techniques were used to determine the distribution of enkephalinlike immunoreactivity in the telencephalon of chicken. The densest accumulation of enkephalinergic neurons and fibers was observed within the paleostriatal complex, the avian equivalent of the mammalian basal ganglia. Numerous small enkephalinergic neurons were observed in both lobus parolfactorius (LPO) and the paleostriatum augmentatum (PA), the two components of the small-celled portion of the paleostriatal complex. The enkephalinergic neurons of LPO-PA appeared to give rise to a dense plexus of enkephalinergic fibers within the large-celled zone of the paleostriatal complex, the paleostriatum primitivum (PP). The distribution of enkephalin within the avian paleostriatial complex, when compared to the distribution of enkephalin within the mammalian basal ganglia, supports previous proposals that $\mathrm{PP}$ is comparable to the mammalian globus pallidus and that PA-LPO are comparable to the caudate-putamen (Karten and Dubbeldam, '73; Kitt and Brauth, '81; Parent and Olivier, '70; Reiner et al., '83). Observations on the development of enkephalinlike immunoreactivity within the chicken paleostriatal complex also support the suggestion that the major component nuclei of the avian paleostriatal complex have correspondents within the mammalian basal ganglia.

Enkephalinlike immunoreactivity was also observed within cell bodies and fibers in other portions of the avian telencephalon. Within the ventrolateral telencephalon, the nucleus accumbens, nucleus of the diagonal band, and tuberculum olfactorium contained enkephalinergic cell bodies and fibers while only enkephalinergic fibers were observed in the portion of the avian telencephalon that has been termed the ventral paleostriatum (Kitt and Brauth, '81; Reiner et al., '83). Within the medial wall of the telencephalon, enkephalinergic fibers were observed in the lateral septal nucleus, while enkephalinergic cell bodies and fibers were observed in the parahippocampal area. Little enkephalinlike immunoreactivity was observed dorsal to the paleostriatal complex except in the hyperstriatum dorsale. Within the hyperstriatum dorsale, a band of enkephalinergic neurons appeared to give rise to an overlying parallel band of dense enkephalinergic fibers.

The distribution of enkephalinlike immunoreactivity within the avian telencephalon thus shows remarkable similarity to that seen in the mammalian telencephalon. The largest accumulation of enkephalinlike immunoreactivity within the telencephalon of both vertebrate classes appears to be found within the ventrolateral wall of the telencephalon, including the basal ganglia. In comparison, much less enkephalinlike immunoreactivity
\end{abstract}

Accepted March 27, 1984.

(c) 1984 ALAN R. LISS, INC. 
is observed in either the mammalian neocortex or in the avian correspondent of mammalian neocortex.

Key words: enkephalin, chicken telencephalon, basal ganglia, immunohistochemistry, opioid peptides

Until the late $60 \mathrm{~s}$, most comparative neuroanatomists believed that the bulk of the telencephalon in birds and reptiles was equivalent to the mammalian basal ganglia (Ariens-Kappers et al., '36; Herrick, '48). The increased tissue mass of the telencephalon of birds and modern reptiles compared to that of amphibians and ancestral reptiles was thought to reflect an expansion of nuclei equivalent to those of the mammalian basal ganglia. In contrast, the increased tissue mass of the mammalian telencephalon as compared to that of amphibians and ancestral reptiles was thought to reflect the proliferation of a new type of telencephalic tissue, neocortex. Although the comprehensive neuroembryological studies of Källén ('51, '62) were clearly incompatible with this viewpoint, the prevailing theory of comparative telencephalic organization was not widely challenged until recent experimental studies began to demonstrate that only a restricted portion of the ventrolateral wall of the telencephalon of birds and reptiles in actuality possess the morphological and histochemical characteristics associated with mammalian basal ganglia (Karten and Dubbeldam, '73; Parent and Olivier, '70; Parent, '73a,b).

Based on modern hodological and histochemical techniques, more precise comparisons between individual nuclei of the mammalian basal ganglia and individual nuclei of the ventrolateral wall of the telencephalon in nonmammals have been possible. In birds, the paleostriatum augmentatum (PA) and lobus parolfactorius (LPO) together have been found to be comparable to the mammalian caudate-putamen (Karten and Dubbeldam, '73; Kitt and Brauth, '81; Parent and Olivier, '70; Reiner et al., '83). Like caudate-putamen, PA and LPO contain mostly small neurons and show distinctively high levels of acetylcholinesterase and dopamine (Bertler et al., '64; Fuxe, '65; Jacobowitz and Palkovits, '74; Juorio and Vogt, '67; Karten, '69; Karten and Dubbeldam, '73; Parent and Olivier, '70). Karten and Dubbeldam ('73) and Parent and Olivier ('70) also found that a large-celled portion of the ventrolateral wall of the avian telencephalon, termed the paleostriatum primitivum (PP), was comparable to the mammalian globus pallidus pars externa $(\mathrm{GPe})$ since both contain low levels of dopamine and acetylcholinesterase. These researchers further proposed that a cell field juxtaposed to the ventral border of the avian PP, termed the nucleus intrapeduncularis (INP), was similar to the globus pallidus pars interna (GPi) of the mammalian basal ganglia. Like the globus pallidus of mammals, the PP-INP complex of pigeon has been reported to receive input from the overlying small-celled zone and give rise to the major extratelencephalic projections of the basal ganglia to thalamic and mesencephalic target nuclei (Karten and Dubbeldam, '73; Kitt and Brauth, '81; Reiner et al., '82a). The avian LPO-PA and PP-INP together are referred to as the paleostriatal complex (PC) (Karten and Dubbeldam, '73).

Both substance $P$ and a variety of the members of the enkephalin family of peptides have been found in high concentrations within the mammalian basal ganglia (Cuello and Kanazawa, '78; Khachaturian et al., '83a; Kanazawa and Jessell, '76; Ljungdahl et al., '78; Miller et al., '78; Pickel et al., '81; Sar et al., '78; Simantov et al., '77; Wamsley et al., '80; Watson et al., '82). Histochemical studies indicate that both substance $\mathrm{P}$ and the enkephalin peptides are contained within neurons of the caudate-putamen. In mammals, substance-P-containing neurons of the caudateputamen are reported to project to the globus pallidus as well as to the midbrain tegmentum, while enkephalinergic neurons are reported to project to the globus pallidus (Del Fiacco et al., '80; Jessell et al., '78; Palkovits et al., '78; Haber and Elde, '81). Although the precise roles of such peptides in the basal ganglia and its projection circuits are unclear, an involvement in neurotransmission seems likely (Nicoll et al., '80; Simantov et al., '76a). Previous histochemical and radioimmunoassay studies of the avian telencephalon (Simantov et al., '76b; Bayon et al., '80) suggest that enkephalinlike peptides are also present in the avian equivalent of the mammalian basal ganglia. Further, studies of the distribution of opiate binding sites in the nervous systems of diverse vertebrate species indicate that high levels of opioid receptors are present in the avian nervous system (Kuhar et al., '73; Pert et al., '74). We have therefore utilized immunohistochemical techniques to determine the distribution of enkephalinlike peptides in the avian telencephalon in order to further explore the similarities and differences in telencephalic organization between birds and mammals. The present study is part of a series of studies examining the distribution of neuropeptides, including substance P (Reiner et al., ' 83 ), within the avian telencephalon.

\section{METHODS}

White Leghorn chickens aged 2 weeks to adult and White Leghorn chicken embryos (ages $4 \frac{1 / 2}{2}$ days to hatching) were used. All animals older than 12-day-old embryos were perfused transcardially with $6 \%$ dextran in $0.1 \mathrm{M}$ phosphate buffer (PB) (pH 7.4) followed by a $4 \%$ paraformaldehyde solution containing $0.1 \mathrm{M} \mathrm{D}, \mathrm{L}-l y s i n e \mathrm{HCl}$ and $0.01 \mathrm{M}$ sodium periodate in PB (McLean and Nakane, '74). All animals older than 18-day-old embryos were deeply anesthetized prior to perfusion. The brains were removed and stored at $4^{\circ} \mathrm{C}$ for an additional 2-6 hours in the same fixative, and then transferred to a fresh solution of $20 \%$ sucrose-PB and stored at $4^{\circ} \mathrm{C}$ overnight. The entire heads of animals younger than 12 days prehatching were immersion fixed in the same fixative as above for $2-6$ hours. The tissue from animals 2 weeks or older was serially sectioned at $40 \mu \mathrm{m}$ using a sliding microtome and collected in staining dishes. Tissue from younger animals was sectioned at 10-15 $\mu \mathrm{m}$ using a cryostat and sections were picked up on gelatin-coated slides. In the case of 4-8-day-old embryos, the entire head was sectioned using a cryostat. Free-floating sections (chicken 2 weeks to adult) and slide-mounted sections (chickens younger than two weeks) were washed three times in PB at room temperature for a total of 30 minutes and then processed using immunohistochemical techniques. 
Free-floating sections were incubated in primary antiserum at a dilution ranging from 1:250 to $1: 1,000$ in $\mathrm{PB}$ with $0.3 \%$ Triton $\mathrm{X}-100$ for $12-36$ hours at $4^{\circ} \mathrm{C}$ in microcentrifuge tubes (Reiner et al., '82b). Sections were then washed three times in PB for a total of 30 minutes and processed according to either the indirect immunofluorescence method of Coons ('58) or the peroxidase-antiperoxidase (PAP) method of Sternberger ('77). For the indirect immunofluorescence method, the sections were incubated for 30-60 minutes at room temperature in goat antirabbit IgG conjugated to fluorescein isothiocyanate (Miles-Yeda) diluted 1:100 in PB with $0.3 \%$ Triton X-100. The sections were subsequently washed three times in PB for a total of 30 minutes, mounted on slides coated with $1 \%$ gelatin, and coverslipped with a solution of glycerin in PB. For the PAP method, the sections were incubated in goat antirabbit IgG (Miles-Yeda) at a 1:100 dilution for 30-60 minutes at room temperature. Following three buffer washes (30 minutes) the sections were then incubated in rabbit peroxidase-antiperoxidase (Dako) at a 1:100 dilution for 30-60 minutes at room temperature. After a 30-minute PB wash, sections were incubated in a solution of 3,3'-diaminobenzidene (DAB) tetrahydrochloride $(100 \mathrm{mg} / 100 \mathrm{ml}$ ) in $0.1 \mathrm{M}$ cacodylate-imidazole buffer ( $\mathrm{pH}$ 7.0) for 20 minutes, followed by incubation for an additional 10 minutes after the addition of hydrogen peroxide (to yield a final concentration of $0.01 \% \mathrm{H}_{2} \mathrm{O}_{2}$ ) to the medium. The sections were then washed several times and mounted on slides. In some cases, the $\mathrm{DAB}$ reaction product was intensified by immersing the sections in $0.1 \%$ osmium tetroxide $\left(\mathrm{OsO}_{4}\right)$ in $\mathrm{PB}$ for 1 minute. After a final buffer wash, the sections were cleared and coverslipped with Permount. The cryostat-sectioned brains of animals younger then 2 weeks posthatching were processed in a similar fashion, except the various antisera were placed as droplets directly on the slide-mounted sections. Telencephalic subdivisions in hatchlings or older birds were identified with the aid of the atlases of Van Tienhoven and Juhasz ('62) and Youngren and Philips ('78). The published studies of Tsai et al. ('81a,b) were used to identify telencephalic subdivisions in embryos. Embryos were staged according to Hamberger and Hamilton ('51). The day of incubation used to identify embryos of a given stage is based on the day of incubation recognized for that stage by Hamberger and Hamilton ('51).

Six different enkephalin antisera were used in the present study: a leucine-enkephalin antiserum (lot A206) and a methionine-enkephalin antiserum (lot A900) (courtesy Kwen-Jen Chang), a leucine-enkephalin antiserum (purchased from Immunonuclear Corporation), a BAM-22P antiserum and a Peptide E antiserum (courtesy of Stanley Watson and Huda Akil), and an antiserum directed against ala-ala-ala-methionine ${ }^{5}$-enkephalin (prepared by Nicholas Brecha and Christine Gall). The methods of antibody preparation and the characterization of the A206 leucine-enkephalin and methionine-enkephalin antisera have been previously described (Miller et al., '78). Although the A206 antiserum appears to show some crossreactivity with members of the dynorphin family of opioid peptides (Reiner, '83), the A206 leucine-enkephalin antiserum and methionineenkephalin antiserum were useful in the present study because the telencephalic immunohistochemical staining pattern using these antisera could be compared directly to the published staining pattern of the mammalian telencephalon based on the use of the same antisera (Sar et al., '78). This furthered the comparative interests of the present study. The other antisera were used in order to specifically label enkephalinergic neurons and fibers in the avian telencephalon, with no crossreactive staining of dynorphinergic neurons and fibers. Although ala-ala-ala-methionine ${ }^{5}$-enkephalin has not been found in the nervous system, an antiserum directed against ala-ala-ala-methionine ${ }^{5}$-enkephalin should, in principle, show considerable crossreactivity with methionine-enkephalin (because of the common Cterminus), but little or no crossreactivity with dynorphin peptides (because of the dissimilarities in the N-terminus). As seen below, the specificity of the ala-ala-ala-methionine ${ }^{5}$. enkephalin antiserum was confirmed in crossblocking studies. The Immunonuclear leucine-enkephalin, the BAM-22P, and the Peptide E antisera all appear to specifically label enkephalinergic perikarya and fibers of the nervous system, as indicated by crossblocking studies or by comparison to the labeling pattern obtained with antisera directed against dynorphin peptides. Since BAM-22P and Peptide E are peptides derived from the same precursor as leucineenkephalin and methionine-enkephalin, namely proenkephalin, all four peptides should be found in the same population of neurons in the avian brain (Khachaturian et al., '83a; Watson et al., '82). The BAM-22P and the Peptide E antisera were used at a 1:250 dilution, while the other antisera were used at a 1:1,000 dilution.

\section{RESULTS \\ Technical considerations}

The A206 leucine-enkephalin antiserum yielded more in tense staining than the methionine-enkephalin antiserum, although the overall pattern of staining was the same for both antisera. Immunoreactive staining with the A206 leu cine-enkephalin antiserum could be blocked with $10 \mu \mathrm{m}$ synthetic leucine-enkephalin, while the staining intensity was reduced slightly (with no alteration in the staining pattern) when this antiserum was blocked with $10 \mu \mathrm{m}$ synthetic methionine-enkephalin. Similarly, staining with the methionine-enkephalin antiserum could be blocked with 10 $\mu \mathrm{m}$ synthetic methionine-enkephalin and reduced slightly (without altering the pattern) by blocking with $10 \mu \mathrm{m}$ leucine-enkephalin. Thus, the A206 leucine-enkephalin antiserum appears to have a slight measure of crossreactivity with methionine-enkephalin and the methionine-enkephalin antiserum appears to have a slight measure of crossreactivity with leucine-enkephalin, as previously reported (less than 1\% in both cases) (Gall et al., '81; Miller et al., '78; Sar et al., '78). Although the strong similarities in the staining pattern for these two antisera may be a reflection of this crossreactivity, the similarities may also considerably reflect the presumed cooccurrence of leucine-enkephalin and methionine-enkephalin in the same neurons in avian brain (Watson et al., ' 82 ). When preadsorbed with 10 $\mu \mathrm{m}$ Dynorphin A (1-8), the staining intensity with the A206 leucine-enkephalin antiserum was considerably reduced. In contrast, the staining intensity and the staining pattern with the ala-ala-ala-methionine ${ }^{5}$-enkephalin antiserum were not obviously affected when this antiserum was blocked with either $10 \mu \mathrm{m}$ Dynorphin A (1-8) or $10 \mu \mathrm{M}$ leucine-enkephalin (Fig. 1). Staining with this antiserum was, however, nearly abolished when it was blocked with $10 \mu \mathrm{M}$ synthetic methionine-enkephalin (Fig. 1). The telencephalic staining pattern with the Immunonuclear leucineenkephalin antiserum was indistinguishable from that obtained with the A206 leucine-enkephalin, the methionineenkephalin, and the ala-ala-ala-methionine ${ }^{5}$-enkephalin antisera, although the staining intensity was somewhat 
less with the Immunonuclear antiserum. Staining with the Immunonuclear antiserum could be blocked with 50-100 $\mu \mathrm{M}$ synthetic leucine-enkephalin, but was unaffected by 50 $\mu \mathrm{M}$ synthetic Dynorphin A (1-17). The telencephalic staining with the BAM-22P antiserum was considerably less intense than with the other enkephalin antisera (except the Peptide E antiserum), but the same cell groups in the ventrolateral and ventromedial telencephalon were stained with the BAM-22P antiserum as with the other antisera. Staining with the BAM-22P antisera could be blocked with 20-50 $\mu \mathrm{M}$ synthetic BAM-22P. This BAM-22P antiserum does not appear to label dynorphinergic perikarya and fibers. For example, the BAM-22P antiserum does not label the strio-nigral tract of chickens and turtles, which is heavily labeled, however, by an antiserum against Dynorphin A (1-17) (courtesy of Stanley Watson and Huda Akil). Finally, the staining intensity with the Peptide $E$ antiserum was less than with the BAM-22P antiserum. The Peptide E antiserum labeled several cell groups in the ventrolateral telencephalon that were heavily labeled by the other enkephalin antisera (perikarya and fibers of nucleus accumbens, perikarya and fibers of the lobus parolfactorius, and fibers of the bed nucleus of the stria terminalis). This result suggests that a Peptide-E-like substance is present in chicken telencephalon in lesser amounts than the other enkephalin peptides under investigation in this study. Staining with the Peptide E antiserum could be blocked with 20-50 $\mu \mathrm{M}$ synthetic Peptide E, but was unaffected by $50 \mu \mathrm{M}$ synthetic Dynorphin A (1-17). The results obtained with all six antisera were consistent and indicate that the staining patterns described here reflect the distribution of enkephalinergic neurons and fibers in the avian telencephalon. A previous study has suggested that both leucine-enkephalin and me thionine-enkephalin are present in the paleostriatal complex of the pigeon and that the latter is in several times greater abundance (Bayon et al., ' 80 ), as also true in mammalian basal ganglia. The recent identification of the enkephalin precursor in adrenal medulla revealed that methionine-enkephalin, leucine-enkephalin, BAM-22P, and Peptide $\mathrm{E}$ all appear to derive from the same precursor molecule (Noda et al., '82; Comb et al., '82), and it is therefore likely that leucine-enkephalin, methionine-enkephalin, BAM-22P, and Peptide E, as detected by immunohistochemical techniques, are present in the same neurons. Due to the greater availability of the A206 antiserum and due to the similarities in the staining pattern observed with all six antisera used in the present study, illustrations presented in this paper (with the exception of Fig. 1) are of sections processed with the A206 antiserum.

$\begin{array}{ll} & \\ \text { Ac } & \text { Nucleus accumbens } \\ \text { AC } & \text { Anterior commissure } \\ \text { FPL } & \text { Fasciculus prosencephali lateralis } \\ \text { HD } & \text { Hyperstriatum dorsale } \\ \text { INP } & \text { Nucleus intrapeduncularis } \\ \text { LMD } & \text { Lamina medullaris dorsalis } \\ \text { LPO } & \text { Lobus parolfactorius } \\ \text { nST } & \text { Bed nucleus of the stria terminalis } \\ \text { PA } & \text { Paleostriatum augmentatum } \\ \text { PC } & \text { Paleostriatal complex } \\ \text { PP } & \text { Paleostriatum primitivum } \\ \text { TO } & \text { Tuberculum olfactorium } \\ \text { V } & \text { Ventricle } \\ \text { VP } & \text { Ventral paleostriatum }\end{array}$

Members of the dynorphin family of peptides, each of which typically contains the amino acid sequence for leucine-enkephalin at its $\mathrm{N}$-terminus, have also been found in the basal forebrain of vertebrates (Khachaturian et al., '83b; Watson et al., '82; Weber et al., '82). Since staining with the leucine-enkephalin antiserum (A206) could be considerably reduced with Dynorphin A (1-8) (a common form of dynorphin found in the brain of mammals, Weber et al., '82), it seems possible some of the staining observed with this antiserum may be due to the presence of dynorphin in the avian telencephalon. Nonetheless, the A206 antiserum labeled the same set of cell groups as several of the other antisera used. For example, the staining pattern and intensity observed with the ala-ala-ala-methionine ${ }^{5}$-enkephalin antiserum were indistinguishable from that produced by the A206 leucine-enkephalin antiserum, and the staining pattern and intensity with the ala-ala-ala-methionine ${ }^{5}$-enkephalin antiserum were not noticeably affected by blocking with Dynorphin A (1-8). These results suggest that if the presence of dynorphin is responsible for some of the observed staining with the A206 antiserum, the dynorphin peptides with which A206 crossreacts must be present in small amounts in much of the avian telencephalon and have a similar distribution to the enkephalin peptides in the remaining portions of the avian telencephalon. Studies of the mammalian basal ganglia indicate that the distribution of dynorphin peptides and the distribution of enkephalin peptides within the basal ganglia are very similar, with the key difference that a population of dynorphinergic striatal neurons projects to the substantia nigra pars reticulata (Vincent et al., ' 82 ; Khachaturian et al., ' $83 a$, b; Watson et al., ' 82 ). Some labeling is seen in the avian strionigral projection system (which in birds includes the fibers of the medial forebrain bundle and the tegmentipedunculopontine region of the midbrain, Reiner et al., '83) in brain material processed with the A206 leucine-enkephalin antiserum. As noted, this pathway in birds is apparently dynorphinergic and is heavily labeled by an antiserum against Dynorphin A (1-17).

\section{Distribution of enkephalinlike immunoreactivity in the hatchling-adult chicken telencephalon}

Among the telencephalic nuclei containing enkephalin positive somata, the lobus parolfactorius (LPO) contained the highest density of labeled cells (Figs. 2-4B). Enkephalin-positive somata (10-13- $\mu$ m diameter) are distributed throughout LPO. The medial aspect of LPO also contained a dense mat of enkephalin-positive fibers surrounding the cell bodies. At least some of these enkephalinergic fibers appeared to be the processes and dendrites of the enkephalinergic neurons. The intensity of fibrous staining was less in the caudal and lateral portions of LPO. The numbers of enkephalin-positive cell bodies also varied within LPO. The highest density was found near the lateral ventricle. In addition, enkephalinergic neurons near the ventricle stained more intensely for the presence of enkephalin. Some of the enkephalin-positive cells in LPO were observed to form small aggregates (Fig. 4B). The paleostriatum augmentatum (PA) also contained a large number of cell bodies which contained enkephalinlike immunoreactivity (ELI) (Figs. 2-4a). The enkephalin-positive cells were variable in shape, with diameters ranging from 8 to $13 \mu \mathrm{m}$. The processes of the enkephalinergic PA neurons exhibited little ELI. In general, the ELI-containing cells were distributed uniformly throughout PA., although some aggregates of ten 

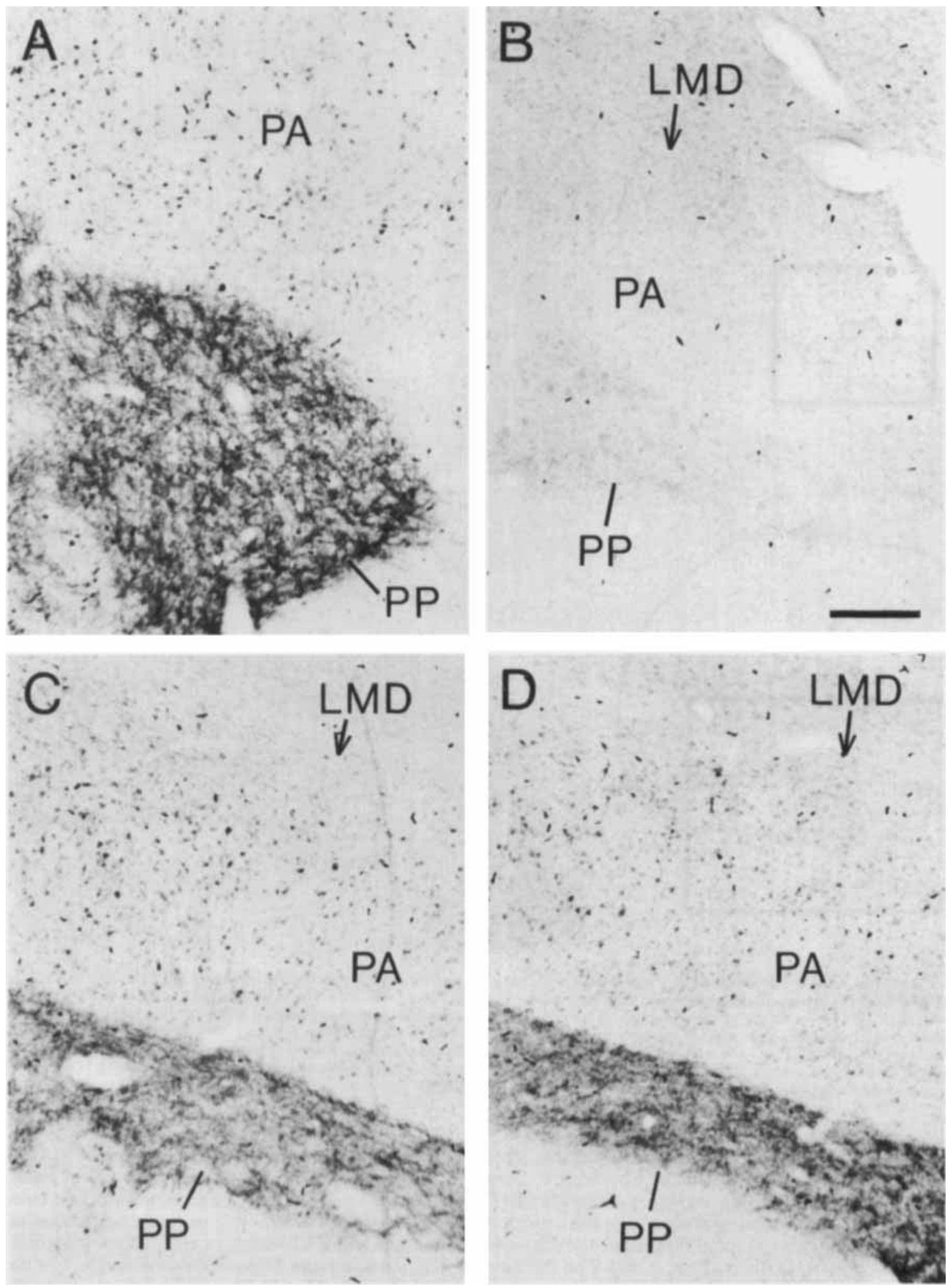

Fig. 1. The staining pattern within the paleostriatal complex of 2-weekold chicken in sections processed with the ala-ala-ala-methionine ${ }^{5}$-enkephalin antiserum (A) and with the ala-ala-ala-methionine ${ }^{5}$-enkephalin antiserum blocked with $10 \mu \mathrm{M}$ methionine-enkephalin (B), with $10 \mu \mathrm{M}$ leucineenkephalin (C) and with $10 \mu \mathrm{M}$ Dynorphin $\mathrm{A}(1-8)(\mathrm{D})$. The staining pattern and intensity with this antiserum was not affected by blocking with either

leucine-enkephalin or with dynorphin A (1-8). Perikaryal staining in PA is of equal intensity in $\mathrm{A}, \mathrm{C}$, and $\mathrm{D}$, as is fiber staining in PP. In contrast, no perikaryal staining is evident in B and only light fiber staining is observed. Residual dark punctate profiles in PA and above the lamina medullaris dorsalis (LMD) in $B$ represent stained red blood cells. The scale bar equals $100 \mu \mathrm{M}$. 
A
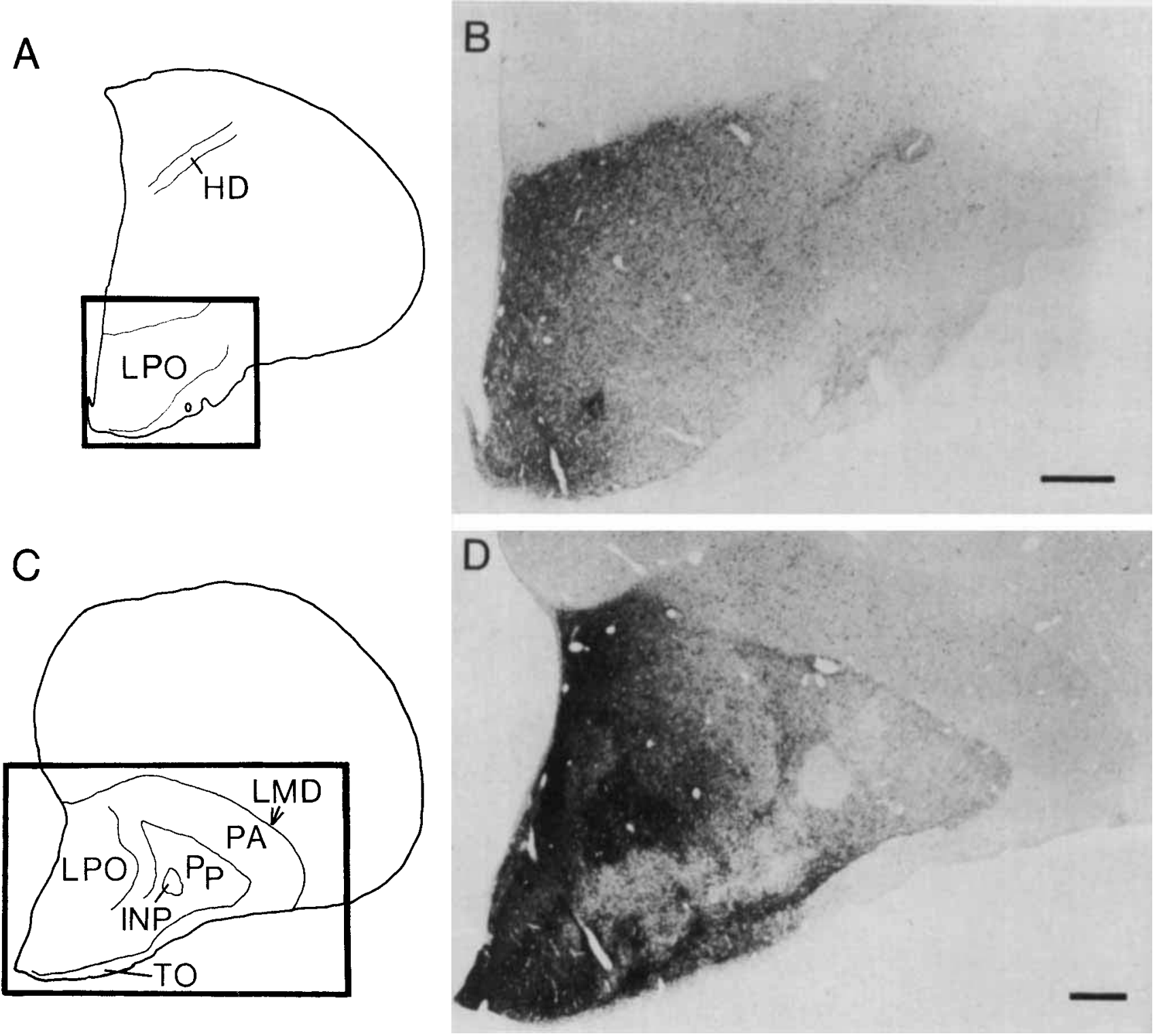

Fig. 2. Transverse sections $(40 \mu \mathrm{M})$ through ventral telencephalon in adult chicken. The outlined area in each schematic $(A, C)$ demarcates the region of telencephalon shown in the photomicrograph to its right $(B, D)$ $A, B$. The paleostriatal complex at the level of the rostral ventral telencephalon. Lobus parolfactorius (LPO) is the only portion of the avian paleostriatal complex present at this level. Enkephalin-positive staining is seen in fibers and somata throughout the nucleus. The density of enkephalin-

to 15 cells were seen within PA. These aggregates were more numerous in the dorsomedial portion of PA. Only more medial PA contained appreciable numbers of ELIpositive fibers. In the lateral porton of PA the neuropil contained only a dustlike enkephalin-positive staining and a few enkephalin-positive fibers (Figs. 2, 3a). The dustlike enkephalin-positive staining presumably represented fine enkephalinergic fibers. Although the fiber staining in PA was generally light, this enkephalin-positive fiber staining distinguished PA from the overlying neostriatum, which was almost totally free of ELI. positive somata and fibers is heaviest near the medial border of the ventral telencephalon. C,D. The paleostriatal complex at the level of the midtelencephalon. Enkephalin-positive cells are distributed throughout the paleostriatum augmentatum (PA) and LPO. The paleostriatum primitivum (PP) contains a dense mat of enkephalin-positive fibers. The intrapeduncular nucleus (INP) is free of enkephalin-positive staining. The scale bars equal $200 \mu \mathrm{M}$.

The region identified as nucleus accumbens (Ac) in birds (Karten and Hodos, '67) contained some of the most intensely ELI-positive fibers and somata in the avian telencephalon (Figs. 3, 5B). The nucleus accumbens contained numerous small ELI-positive cells with soma diameters of $10-12 \mu \mathrm{m}$ and some larger enkephalinergic cells with soma measuring 20-25 $\mu \mathrm{m}$. The ELI-containing somata in Ac were most numerous near the lateral ventricle. The large ELI-containing somata were unique to Ac and were not found in any other region of the telencephalon. On the basis of ELI alone, it was difficult to identify the precise bounda- 
A
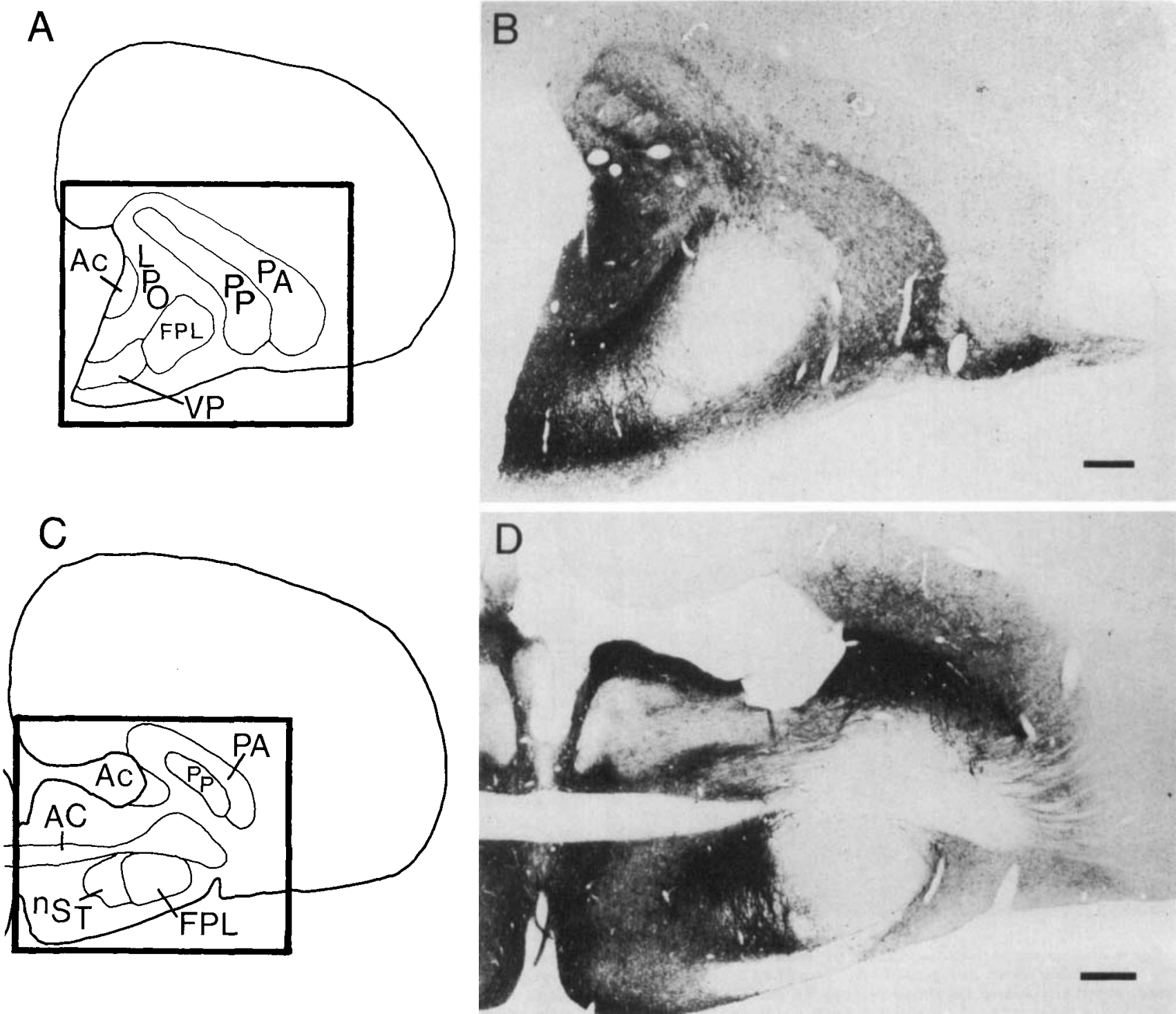

Fig. 3.A,B. Transverse section $(40 \mu \mathrm{m})$ through the telencephalon of adult chicken at the level of the lateral forebrain bundle (FPL) just rostral to the anterior commissure (AC). The ventral paleostriatum (VP) is present at this level, as is nucleus accumbens (Ac). Both contain intense enkephalinpositive fiber staining. The Ac also contains enkephalin-positive cells, but these are not evident in this photomicrograph due to the intense fiber staining. The tuberculum olfactorium (not labeled in A) is located ventral to the ventral paleostriatum. C,D. Transverse section $(40 \mu \mathrm{m})$ through the caudal telencephalon at the level of the anterior commissure. In addition to Ac, PA, and PP, the bed nucleus of the stria terminalis (nST) is present. The nST contains thick bundles of enkephalin-positive fibers. The region of enkephalin-positive fibers along the ventromedial edge of the telencephalon is the nucleus of the diagonal band (not labeled in C). The scale bars equal $200 \mu \mathrm{m}$. ries between PA, LPO, and Ac. The boundary between LPO and Ac can be defined, however, by the differential immunohistochemical staining of these two regions for substance P (Reiner et al., '83).

The PP was distinguished from PA and LPO by the presence of a dense mat of thick, coarse ELI-positive fibers (Figs. 2-4a). This staining was evenly distributed throughout PP. A few ELI-positive somata were seen in PP, close to the border of PA or LPO. No enkephalinergic neurons were seen within other portions of PP. Thus, the enkephalinergic fibers within PP presumably largely represented the fibers and terminations of the enkephalinergic PA neurons upon the neurons of PP. Within PP, the ELI-positive fibers showed no consistent orientation. No enkephalin-positive cell or fiber staining was observed in INP.

Several other cell groups of the ventrolateral wall of the telencephalon contained ELI-positive somata, including the tuberculum olfactorium (TO) and the nucleus of the fasciculus diagonalis Brocae (nFDB) (Figs. 2, 3, 6). The ELIpositive cells in TO were small (10-12 $\mu \mathrm{m}$ in diameter) and multipolar. These cells were found in the rostral half of the telencephalon along its ventral border. Only faint fiber staining was seen in most of TO. Enkephalinergic somata in $\mathrm{nFDB}$ were surrounded by a dense meshwork of enkephalinergic fibers and were approximately $16 \mu \mathrm{m}$ in diameter. The region of the avian telecephalon ventral to nucleus 


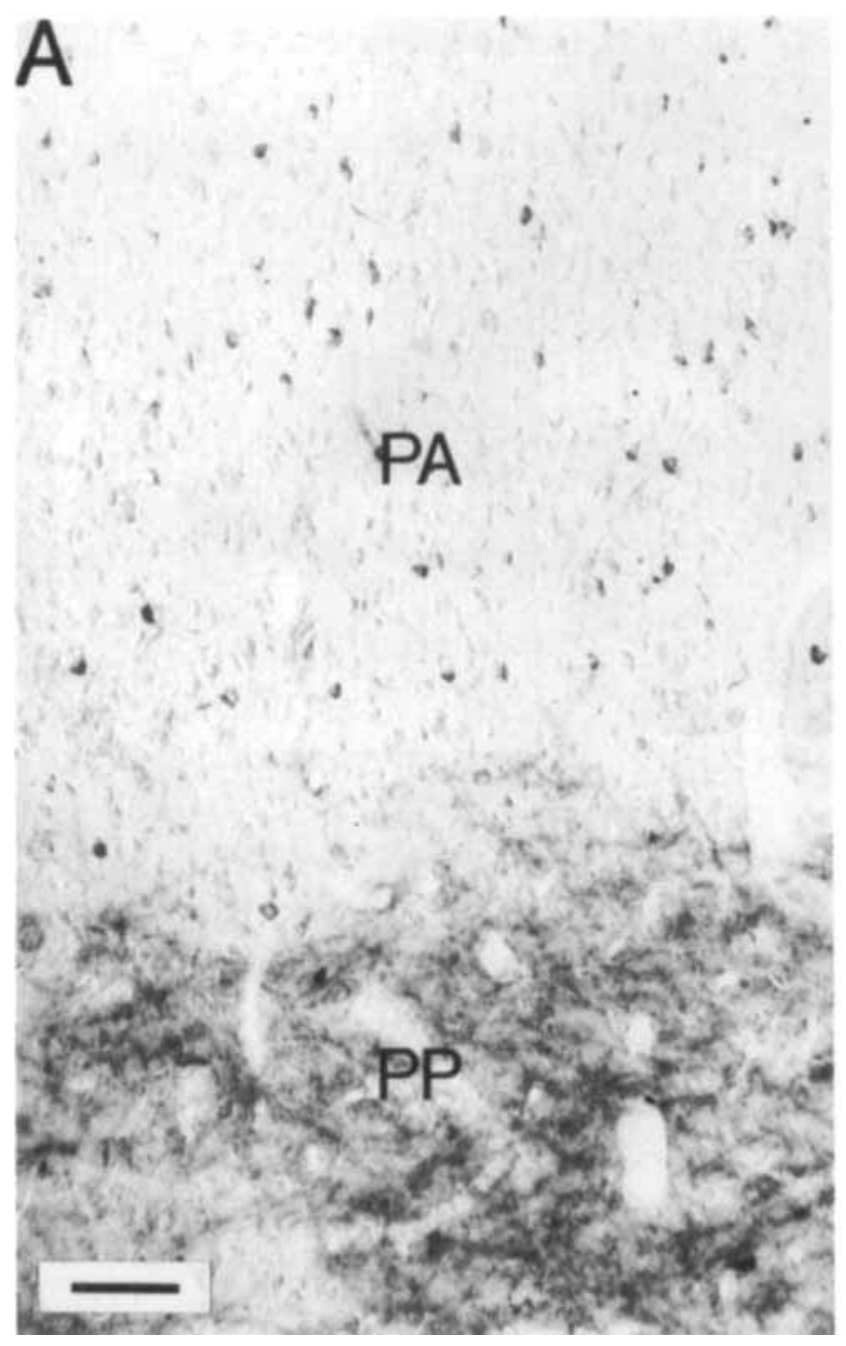

Fig. 4. High-power photomicrographs of the transverse section through the telencephalon shown in Figure 3B. A. The pattern of enkephalin like immunoreactivity seen at the border between PA and PP. The PP can be identified by the presence of a dense mat of enkephalin-positive fibers. The $\mathrm{PA}$ is distinguished by uniform distribution of enkephalin-positive cell bod

accumbens and dorsal to the tuberculum olfactorium has been termed the ventral paleostriatum (Kitt and Brauth, '81; Reiner et al., '83). The ventral paleostriatum was seen to contain a dense network of enkephalinergic fibers in the present study. The fiber staining observed was similar in appearance to that within PP. No enkephalinergic cell bodies were seen in the ventral paleostriatum (Figs. 2, 3).

In addition to PP and the ventral paleostriatum, several other cell groups of the ventral telencephalon were seen to contain ELI-positive fibers but little or no perikaryal immunoreactivity. These nuclei included the lateral septal nucleus (SL) and the bed nucleus of stria terminalis (nST) (Fig. 3). In nST the enkephalinergic fibers formed thick bundles which ran parallel to the dorsal-ventral axis of the telencephalon at the level of the anterior commissure. In SL, ELI was concentrated along the lateral ventricle. Unlabeled somata in SL were often observed to be outlined by intensely ELI-positive fibers, but enkephalinergic peri-

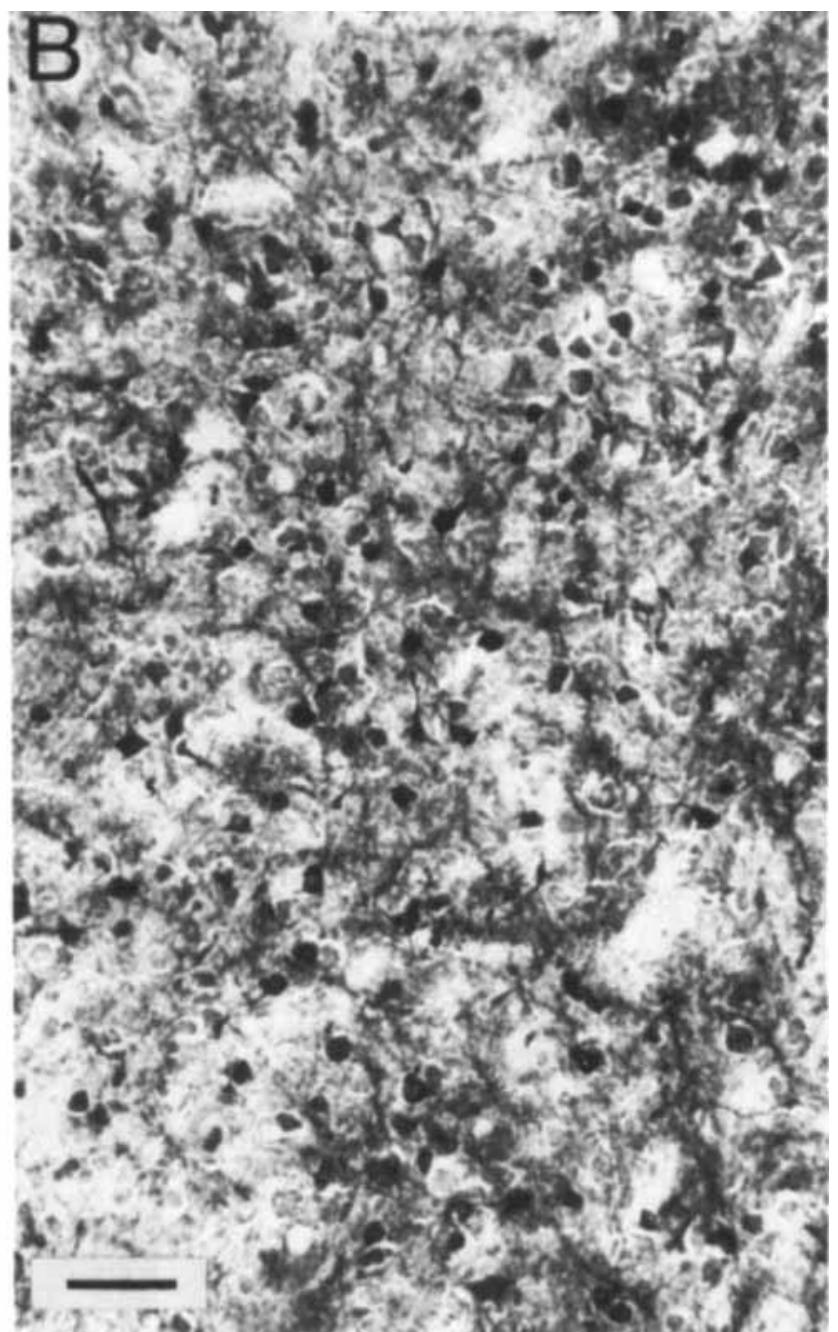

ies and by a light level of enkephalin-positive fiber staining. $\mathbf{B}$. The pattern of enkephalinlike immunoreactivity seen in LPO. The enkephalin-positive somata are more numerous in LPO than PA and are embedded in a dense meshwork of enkephalin-positive fibers. The scale bars equal $50 \mu \mathrm{m}$.

karya were not seen in SL. Blähser and Dubois ('80), however, have reported the presence of enkephalinergic cell bodies within the SL of chicken. We have observed enkephalinergic neurons within SL in colchicine-treated pigeons using the A206 antiserum (Reiner and Karten, unpublished observations).

Very little ELI was observed in the portion of the avian telencephalon overlying the lamina medullaris dorsalis (LMD), the dorsal border of the paleostriatal complex. Within the hyperstriatum, however, a band of small enkephalinergic neurons $(10 \mu \mathrm{m})$ was found to lie within the hyperstriatum dorsale (HD), just dorsal to the hyperstriatum ventrale (Fig. 5a). These enkephalinergic neurons of HD appeared to give rise to enkephalinergic processes that formed a band of enkephalinergic fibers that was juxtaposed to the dorsal edge of the band of enkephalinergic cell bodies. Some additional enkephalinergic neurons were also observed more caudally within the parahippocampal area. 

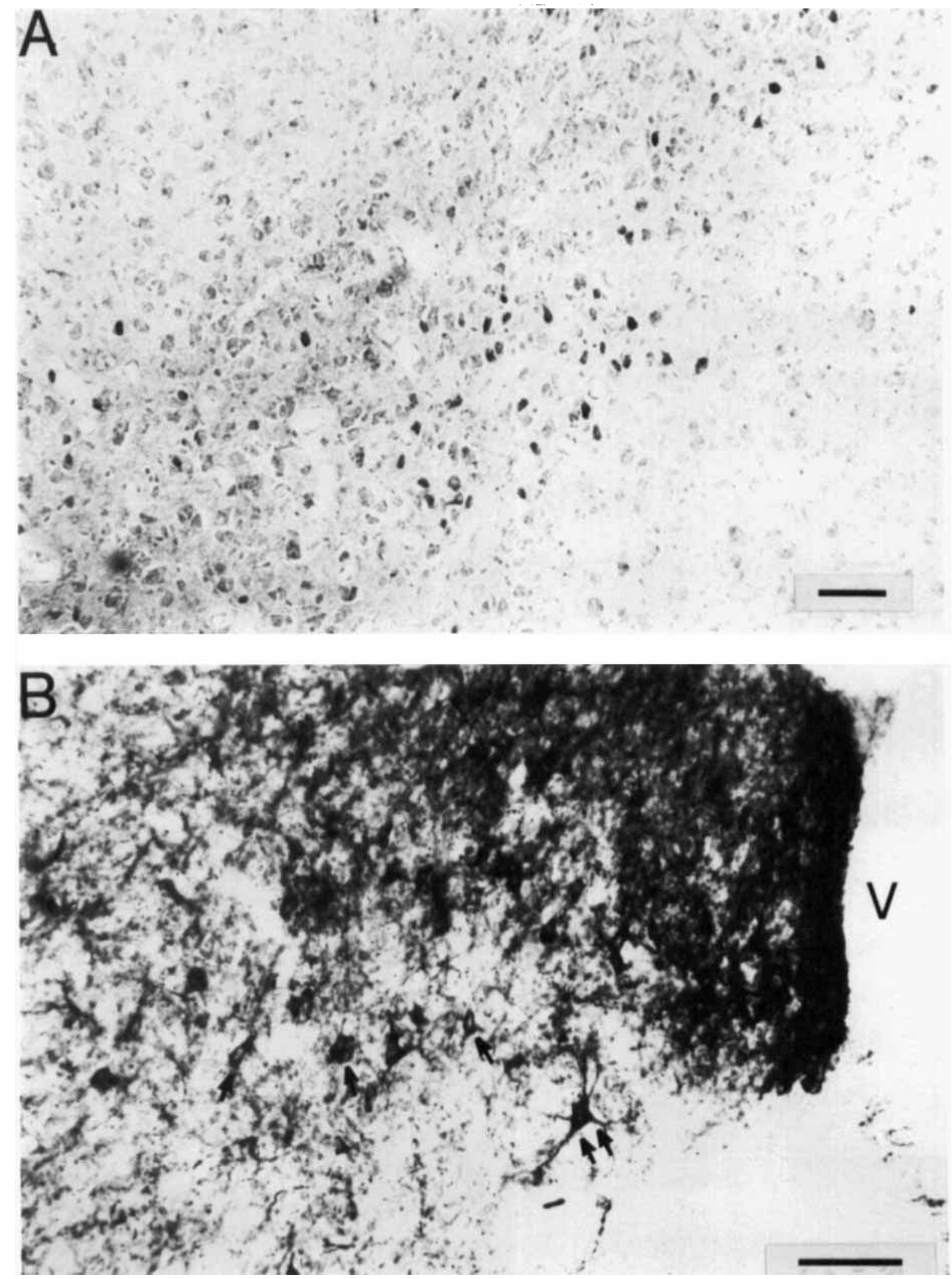

Fig. 5. High-power photomicrographs of enkephalin-positive staining in the area of the hyperstriatum dorsale (A) and nucleus accumbens (B). Both photomicrographs are of transverse sections. Medial is to the left in A and to the right in B. A. The majority of enkephalin-positive cells are adjacent and deep to a band of enkephalin-positive fibers. The darkely labeled cells are positive for enkephalin, while the faintly stained cells are nonimmuno- reactive cells that have been darkened by the osmium intensification used to enhance the immunoreactive staining. B. Dense enkephalinergic fiber staining can be seen in the nucleus accumbens (Ac), especially along its medial border. Small (single arrows) and large (double-arrows) enkephalinpositive neurons are identifiable. The scale bars equal $50 \mu \mathrm{m}$ 

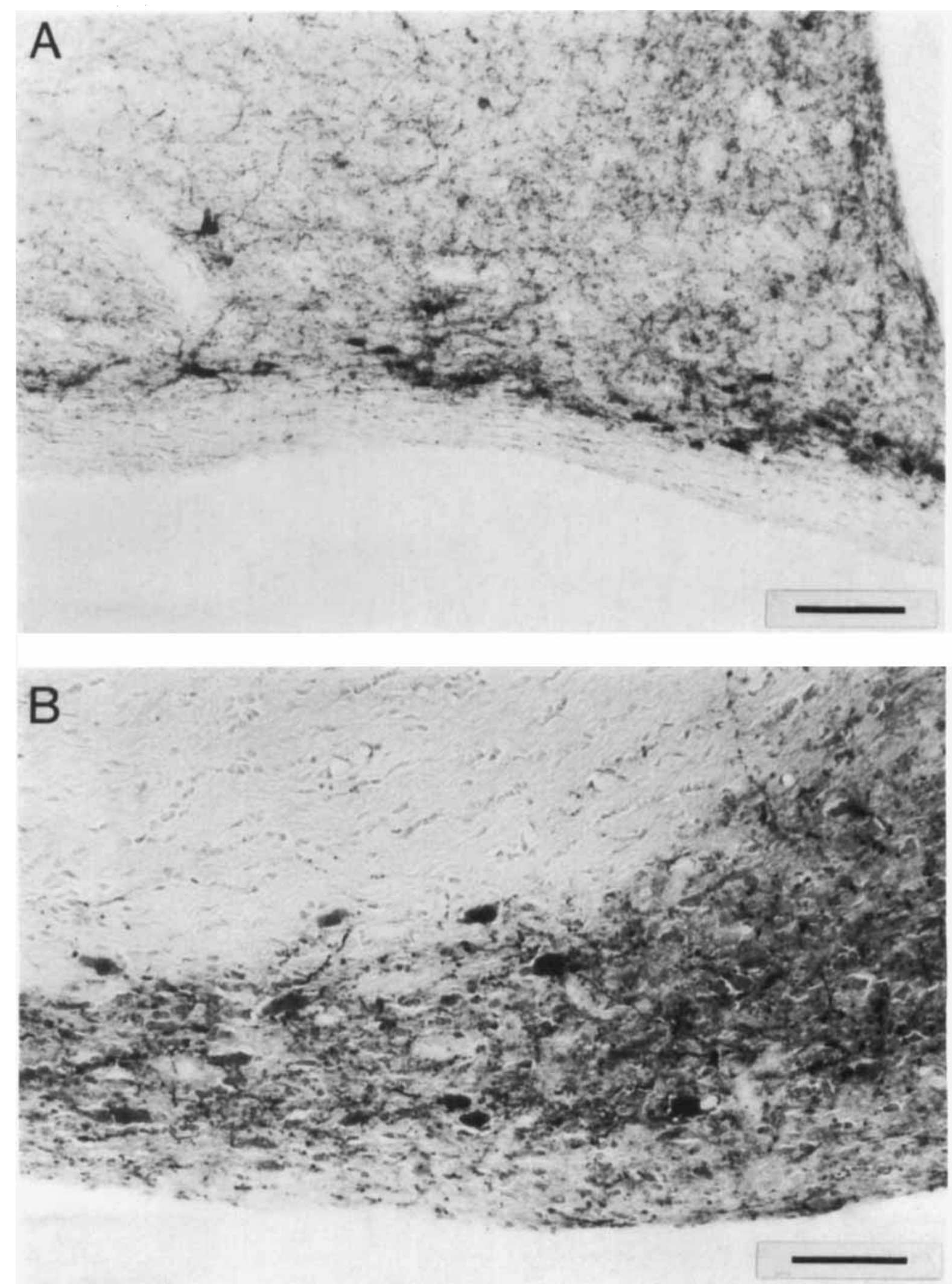

Fig. 6. High-power photomicrograph of enkephalin-positive staining in the area of the olfactory tubercle (A) and the nucleus of the diagonal band of Broca (B). Both the olfactory tubercle and the nucleus of the diagonal band are situated along: the ventromedial border of the telencephalon and contain enkephalin-positive fibers and cells. The unlabeled region dorsal to the nucleus of the diagonal band in B represents the tractus septomesencephalicus. Both photomicrographs are of transverse sections and medial is to the right in both. The scale bars equal $50 \mu \mathrm{m}$. 


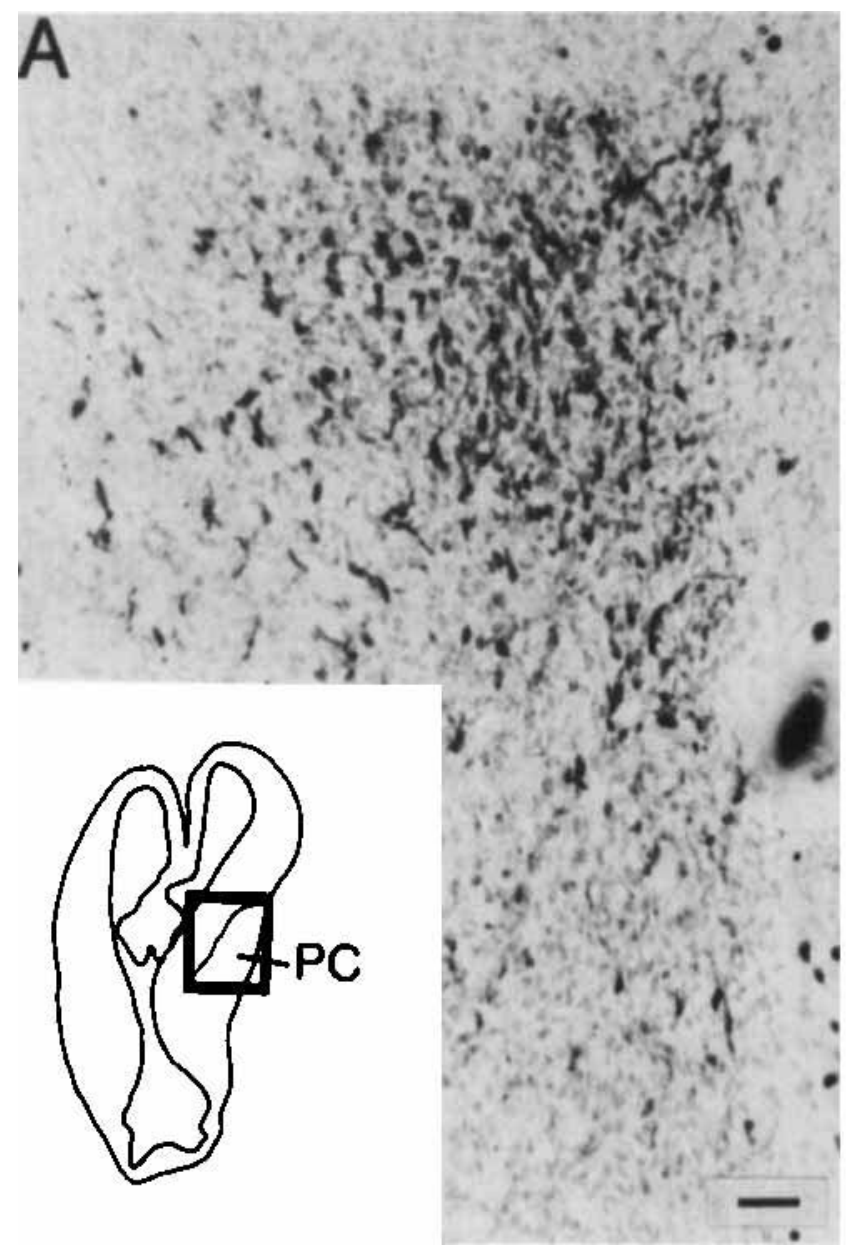

Fig. 7. Transverse section $(10 \mu \mathrm{m})$ of the developing paleostriatal complex of a stage 28 chick embryo. A. The outlined area of the schematic in the inset demarcates the region of telencephalon shown in the photomicrograph. Enkephalin-positive somata are found in the ventrolateral portion of the developing paleostriatal complex. B. High-power photomicrograph of

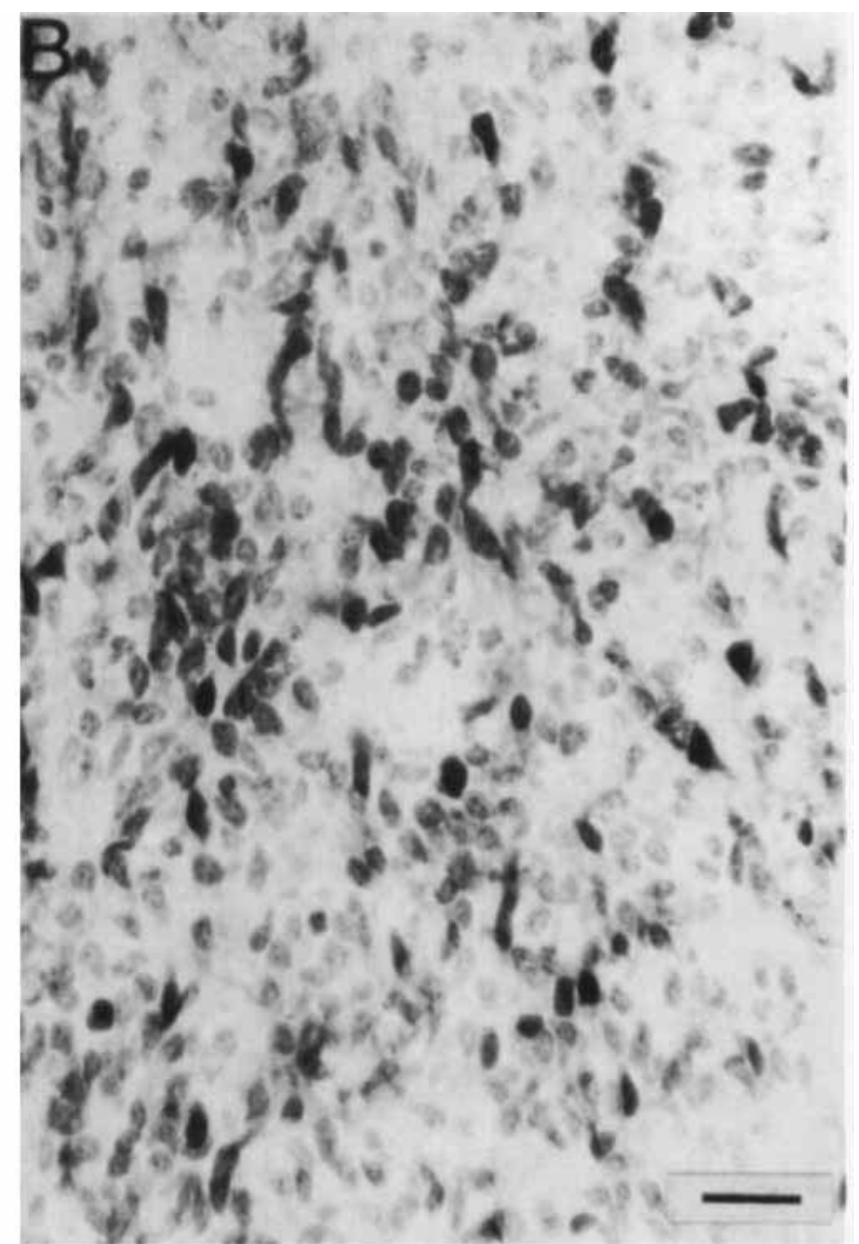

cells in PC. The enkephalin-positive cells were ovoid with no obvious enkephalin-positive processes. The intensity of staining varies in the somata shown. Faintly stained cells are the result of the osmium intensification. The scale bars equal $20 \mu \mathrm{m}$.

their births on day 6 and have nearly completed their births by day 8 , while neurons of more medial LPO have birth dates that range from day 7 to day 9 . Within $24-48$ hours of cell birth, neurons reach their final adult positions (Tsai et al., '81b).

We first observed ELI in the basal telencephalon of the stage 26 chick embryo (not shown). In these embryos enkephalinlike immunoreactivity was restricted to a few neurons in the most lateral portion of the ventral wall of the telencephalon. By stage 28, enkephalin-positive neurons were present along the lateral wall of the telencephalon in sufficient numbers to suggest the outline of the developing paleostriatal complex (PC) (Fig. 7). These neurons were small $(10 \mu \mathrm{m})$ ovoid cells with no obvious stained processes. These earliest enkephalinergic neurons presumably were among the first PA neurons to migrate from the prolifera. tive zone. By stage 30, enkephalin-positive staining was evident in the lateral wall throughout the region of the embryonic paleostriatal complex (Fig. 8). The enkephalinergic cells had begun to develop processes, as evidenced by the appearance of short enkephalin-positive processes. their births on day 5, while successively more medial PA neurons begin their births later. Thus, neurons of medial PA tend to be born on day 6 . Neurons of lateral LPO begin ephalinergic systems within the avian basal gan Tsai et al. ('81a) have reported that neurons of the PP and ventral paleostriatum are all born on day 4 , while neuron of PA and LPO are born subsequently in an "outside-in" of PA and LPO are born subsequently in an "outside-in" 

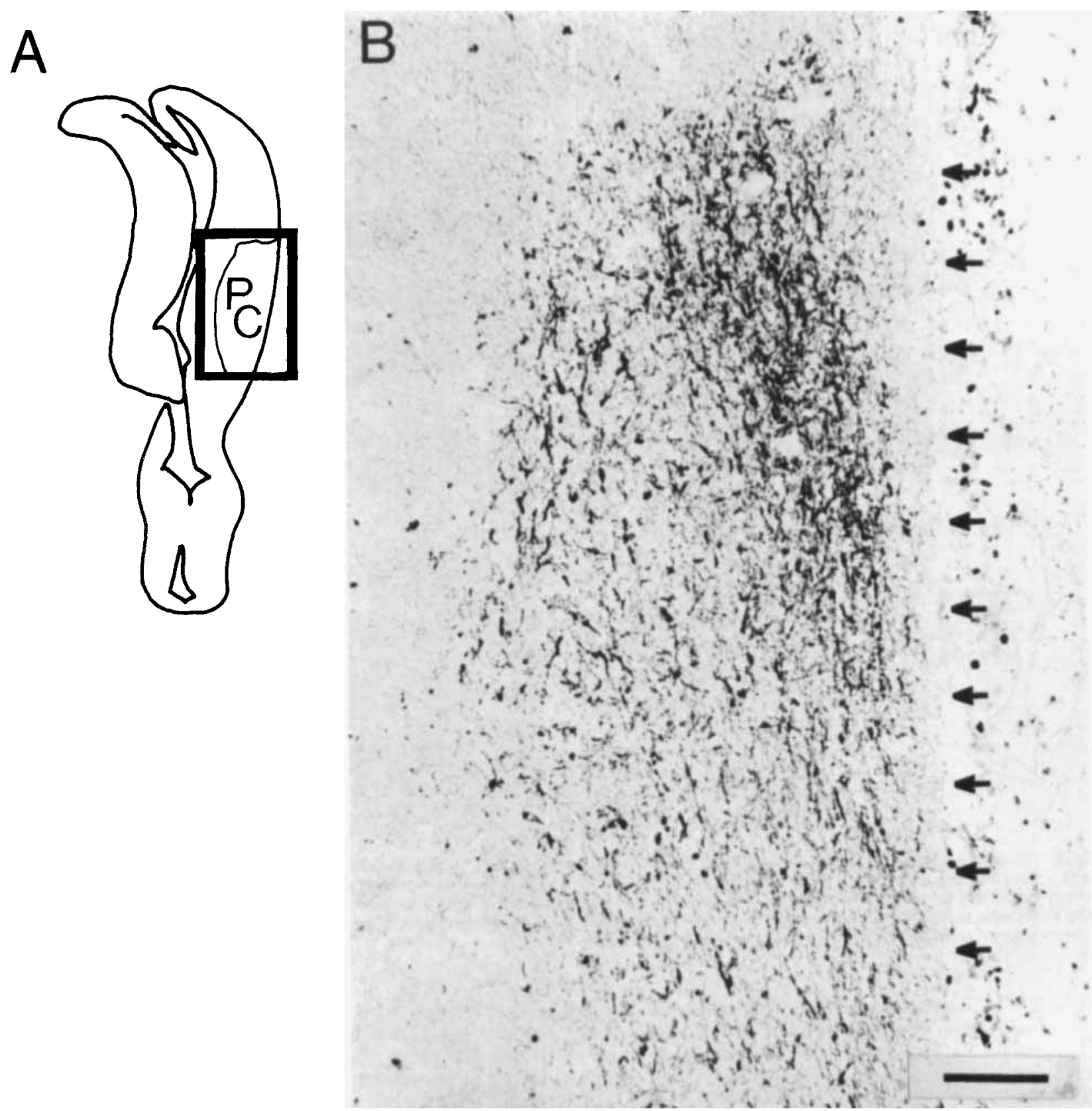

Fig. 8. Transverse section $(10 \mu \mathrm{m})$ through the developing paleostriatal complex of a stage 30 chick embryo. The outlined area in the schematic (A) demarcates the region of the telencephalon shown in the photomicrograph at the right $(B)$. None of the individual telencephalic nuclei show enkephalin-positive staining patterns similar to that of hatchling or adult chick- ens at this stage. The distribution of enkephalin-positive cells is similar to that of stage 28 , but the enkephalinergic cells of stage 30 embryos exhibit enkephalin-positive processes. The border of the brain is indicated by arrows. The scale bar equals $100 \mu \mathrm{m}$.
Although the neurons of PP had completed their migration by this stage, enkephalinergic fibers within PP did not yet form a weblike plexus, as typical in the adult. The portions of the ventral telencephalon along the wall of the lateral ventricle were devoid of ELI. By stage 35, the basal telencephalon was seen to assume a much more adultlike appearance in terms of its cytoarchitecture and pattern of ELI (Fig. 9). At this time it was possible to distinguish two different enkephalin-positive cell groups in the rostral por- tion of the telencephalon. The first was composed of small, round, closely packed cells located dorsally and laterally in the developing PC. The second group was situated medially and was composed of larger cells with more elaborate processes. These two cell groups represented PA and LPO, respectively. The histogenesis of the paleostriatal complex is nearly complete by stage 35 (Tsai et al., '81a), and LPO and PA were found to be full of enkephalinergic neurons throughout nearly their entire mediolateral extents by this 

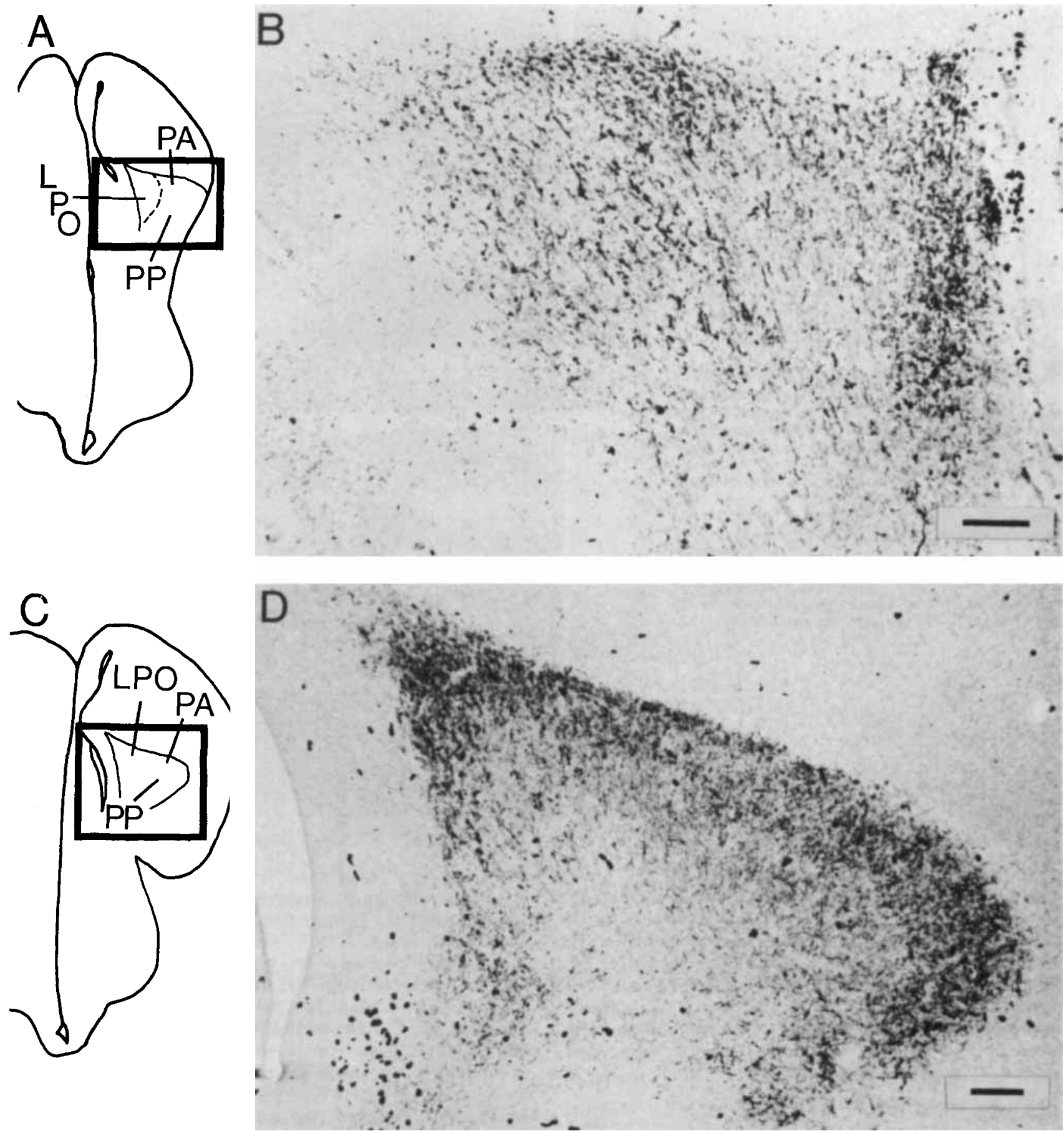

Fig. 9. Transverse sections $(10 \mu \mathrm{m})$ of the developing paleostriatal complex of stage 35 chick embryo. Outlined areas in schematics (A,C) indicate the region of telencephalon shown in the photomicrographs to their right (B,D). A,B. At rostral levels two distinct cell groups can be discerned on the basis of enkephalin-positive staining. The medial group contains enkephalin-positive cells that have elaborate enkephalin-positive processes. This medial group represents LPO. Located laterally is a group of more numer-

ous small, tightly clustered enkephalin-positive cells that represent PA. The $\mathrm{PP}$ is ventromedial to the enkephalin-positive fibers of PA. C,D. In the caudal telencephalon a crescent-shaped zone of enkephalin-positive cells can be seen. The dense mat of enkephalin-positive fibers located medially and ventrally to the enkephalin-positive cells is the paleostriatum primitivum. The scale bars equal $100 \mu \mathrm{m}$.

stage. Thick enkephalinergic fibers were seen to leave PA and enter PP. A medial zone of the ventral telencephalic wall, however, was still free of enkephalin-positive staining at stage 35 . By stage 38 , the ventral telencephalon is recognizably adultlike in its cytoarchitecture, and the pattern of
ELI in the ventral telencephalon was also recognizably adultlike by this stage (Fig. 10). The major difference between the adult and the stage 38 pattern of immunoreactivity was the higher density of enkephalinergic neurons found in the embryonic PA (Fig. 10C). The lower density of enke- 


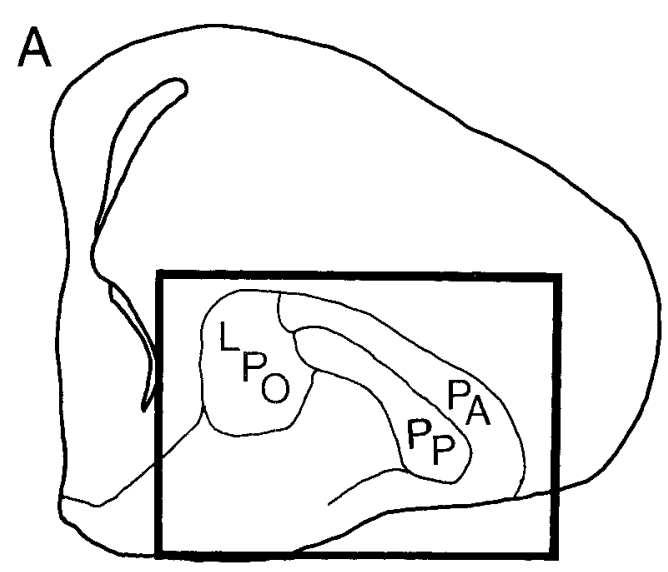

Fig. 10. Transverse section $(10 \mu \mathrm{m})$ through the developing paleostriatal complex of a stage 38 (12 days old) chick. Outlined area in schematic (A) demarcates the region of the telencephlon shown in the photomicrograph to its immediate right $(B)$. The pattern of enkephalinlike immunoreactivity is recognizably similar to that of an adult or hatchling chicken. A high-power photomicrograph of the border between PA and PP (C) shows that the processes of the cells in PA are more numerous and appear thicker at this stage than in the adult. The enkephalin-positive cells are also more tightly packed at this stage than in the adult. Although PP contains numerous enkephalin-positive fibers, these fibers do not form the dense mat of enkephalinergic fibers characteristic of adult or hatchling PP. The scale bars equal $50 \mu \mathrm{m}$.
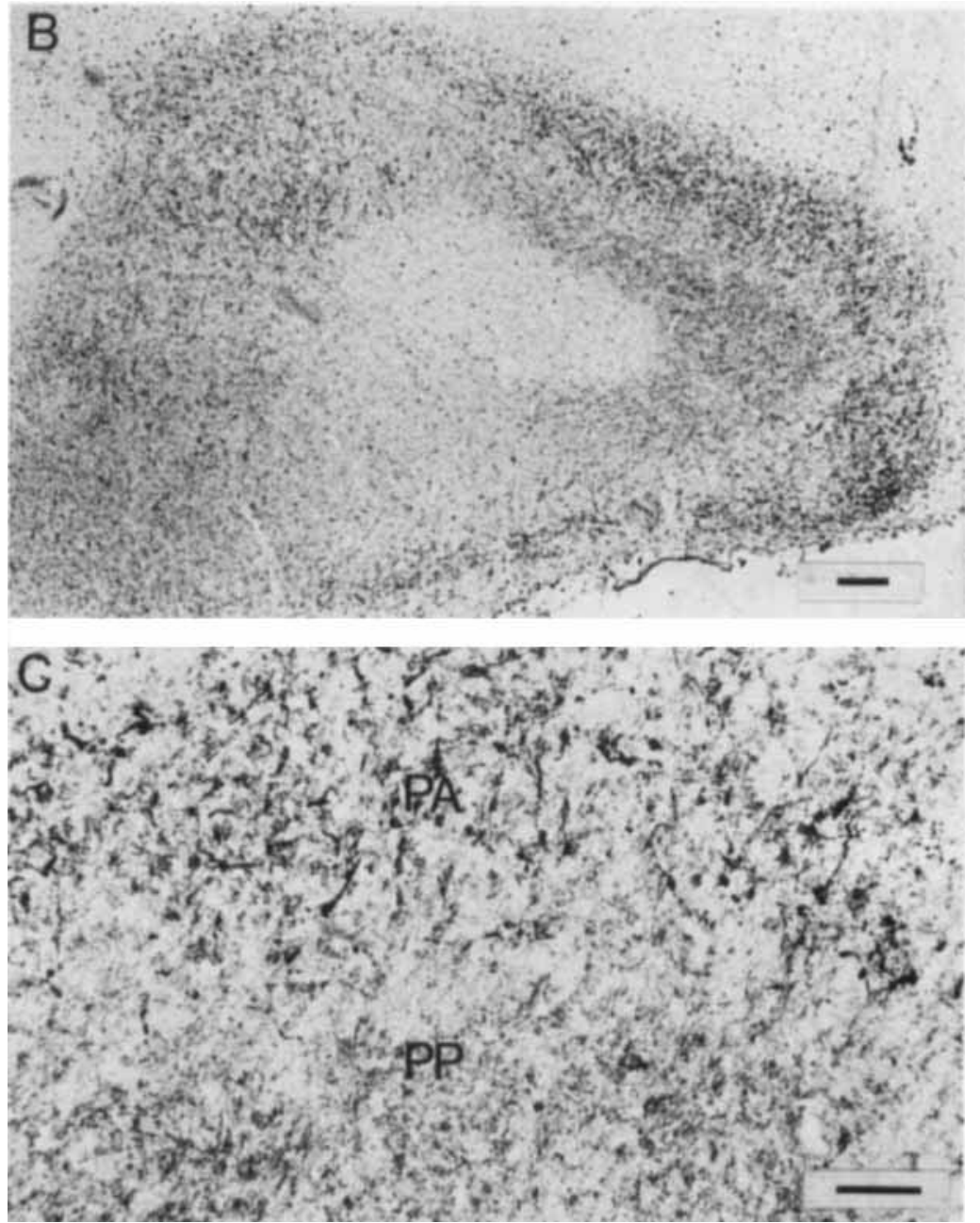

phalin-positive neurons seen in the adult may be due to decreases in the amount of enkephalin peptides stored or synthesized by individual PA neurons, increases in the volume of neuronal processes (dendrites and axons) or glial elements in PA, or mortality among enkephalinergic neurons in PA. The developmental observations presented here suggest that neurons of PA and LPO begin to synthesize immunohistochemically detectible amounts of enkephalin shortly (within approximately 24 hours) after their migration to their final adult positions.

\section{DISCUSSION}

On the basis of cytoarchitecture, cytochemistry, and connectivity, several authors (Dube and Parent, '81; Karten and Dubbledam, '73; Kitt and Brauth, '81; Parent and Olivier, '70; Reiner et al., '83) have suggested that the avian paleostriatal complex contains component nuclei whose correspondents can be identified within the mammalian basal ganglia. These authors have proposed that LPO and PA are similar to the mammalian caudate-putamen for several reasons. First, like caudate-putamen, LPO and $\mathrm{PA}$ receive descending input from dorsal telencephalic areas (dorsal lateral telencephalon and hyperstriatum ventrale) (Brauth et al., '78, Brauth, personal communication) and ascending input from dopaminergic tegmental cell groups (nucleus tegmentipedunculopontinus) (Bertler et al., '64; Brauth et al., '78; Karten and Dubbeldam, '73). Second, like caudate-putamen, LPO and PA have a major output to a large-celled portion of the basal ganglia (termed the paleostriatum primitivum, PP, in bird) that is largely free of acetylcholinesterase and catecholamines (Dube and Parent, '81; Fuxe, '65; Karten and Dubbledam, '73; Kitt and Brauth, '81) and that gives rise to the major extratelencephalic projections of the basal ganglia to subthalmic, thalamic, and tegmental targets (Carpenter, '76; Nauta and Mehler, '66; Nauta, '79). Third, like caudate-putamen, LPO and PA contain a dense accumulation of acetylcholinesterase-containing fibers and dopaminergic fibers (Dube and Parent, '81; Karten and Dubbledam, '73; Parent and Olivier, '70). Finally, like caudate-putamen, LPO and PA contain substance-P-positive neurons (Jessell et al., '78; Palkovits et al., '78; Reiner et al., '83) that give rise to a substance-Pcontaining projection to the tegmental dopaminergic cell groups (Jessell et al., '78; Palkovits et al., '78; Reiner et al., '83). Similar pathway-tracing techniques and immunohistochemical methods have also been used by the various authors cited above to show that the avian PP is comparable to the mammalian globus pallidus. 
The present study furthers the argument that the mammalian and avian telencephala are comparable with respect to the histochemical and anatomical organization of their ventrolateral regions. The distribution of enkephalinlike immunoreactivity observed in the the chicken basal ganglia, or paleostriatal complex, is comparable to that reported in the rat (Khachaturian et al., '83a,b; Sar et al., '78; Simantov et al., '77; Wamsley et al., '80; Watson et al., '82). Enkephalin-positive somata are present throughout the small-celled zone of the mammalian basal ganglia (caudateputamen and nucleus accumbens). We have found that enkephalinergic neurons are also present throughout the small-celled zone of the avian basal ganglia (comprising PA and LPO). Early experimental neuroanatomical studies of the avian telencephalon had been uncertain of the mammalian correspondent of the avian LPO (Karten and Dubbeldam, '73; Brauth et al., '78). Recent studies have shown that LPO gives rise to a descending substance-P-containing projection to the avian correspondent of the mammalian substantia nigra pars reticulata (Kitt and Brauth, '81; Reiner et al., '83). Since the substantia nigra pars reticulata receives a substance-P-positive input from the caudate-putamen (Jessell et al., '78; Palkovits et al., '78), the hodological and substance $\mathrm{P}$ immunohistochemical data in bird suggest that LPO is comparable to caudate-putamen. The presence of enkephalinergic neurons throughout LPO and PA supports the suggestion that LPO and PA together comprise the avian correspondent of the mammalian caudate-putamen. In mammals, enkephalin-positive fibers and terminals are found in the globus pallidus and are reported to originate from enkephalin-positive neurons of the caudate-putamen (Del Fiacco et al., '82; Haber and Elde, '81). The avian PA also appears to send enkephalinergic fibers into $\mathrm{PP}$, the proposed avian equivalent of the mammalian globus pallidus.

The presence of a dense meshwork of enkephalinergic fibers within the avian ventral paleostriatum, as also found in the mammalian ventral pallidum (or substantia innominata), is consistent with the previous observations on similarities between these two structures. Kitt and Brauth ('81) have noted that the ventral paleostriatum of birds and the ventral pallidum of mammals have similar efferent projections, while Reiner et al. ('83) have noted that the avian ventral paleostriatum contains a dense plexus of substanceP-positive fibers, as has been reported for the mammalian ventral pallidum (Cuello and Kanazawa, '78; Ljungdahl et al., '78). Based on substance $P$ distribution, Reiner et al. ('83) have also suggested that the structure termed nucleus accumbens in pigeons does not correspond to the structure termed nucleus accumbens in mammals. Reiner et al., ('83) have proposed that the avian equivalent of the mammalian nucleus accumbens in actuality is contained within the rostromedial portion of LPO. Thus, the structure termed the nucleus accumbens in this paper in all likelihood does not correspond to that termed the nucleus accumbens in mammals. The structure termed nucleus accumbens here may correspond more closely to some portion of the mammalian bed nucleus of the stria terminalis (Reiner et al., '83). Consistent with this possibility, the mammalian bed nucleus of the stria terminalis and the avian nucleus accumbens both contain uniquely large enkephalinergic neurons. The present observations on the distribution of enkephalinlike immunoreactivity in the chicken paleostriatal complex are consistent with the observed distribu- tion of ELI in the paleostriatal complex of pigeon (Bayon et al., '80; Reiner and Karten, unpub. obs.).

Recently investigators have attempted to categorize areas of the mammalian basal telencephalon as "striatal" or "pallidal"in nature, based on neuroanatomical and histochemical similarities to the caudate-putamen or globus pallidus, respectively (Heimer, '78; Newman et al., ' $80 \mathrm{a}, \mathrm{b}$; Switzer and Hill, '79). The patterns of enkephalinlike immunoreactivity reported for the rat indicate that "striatal" areas are characterized by the presence of enkephalinergic neurons while "pallidal" areas are characterized by the presence of a dense plexus of thick, coarse enkephalinergic fibers (Khachaturian et al., '83a; Sar et al., '78; Wamsley et al., '80). The mammalian "striatal" groups include the nucleus accumbens and the tuberculum olfactorium, in addition to caudate-putamen. In the bird, PA, LPO, Ac, and possibly TO have been reported to have "striatal" connections (Brauth et al., '78; Karten and Dubbledam, '73; Kitt and Brauth, '81). The present study has shown that these same cell groups also show a typically "striatal" histochemical characteristic, the presence of numerous enkephalinergic neurons. As noted above, the structure termed nucleus accumbens in birds in all likelihood corresponds to a portion of the bed nucleus of the stria terminalis in mammals. The mammalian "pallidal" groups include GP and the ventral pallidum. In birds, PP and ventral paleostriatum appear to show typically "pallidal" connections (Brauth et al., '78; Karten and Dubbeldam, '73; Kitt and Brauth, '81). As noted, both PP and the ventral paleostriatum show a typically "pallidal" histochemical characteristic, the presence of a dense plexus of enkephalinergic fibers. In addition, a dense plexus of substance-P-containing fibers is present in both $\mathrm{PP}$ and the ventral paleostriatum as well as in their mammalian counterparts (Reiner et al., '83).

Our developmental observations are also consistent with the proposed homology between the avian paleostriatal complex and the mammalian basal ganglia. As in birds, neurons of the large-celled portion of the mammalian basal ganglia (the globus pallidus) have an earlier birthdate than the neurons of the small-celled component (caudate-putamen). Also as in birds, the neurons of the small-celled component of the mammalian basal ganglia show an "outsidein" histogenetic gradient (Sidman and Angevine, '62; ten Donkelaar and Dederen, '79). The sequence of appearance of ELI in the topographically different portions of the paleostriatal complex of developing chicken mirrors the histogenetic gradient seen by Tsai et al. ('81a,b) in that ELI first appears in neurons of far lateral PA/LPO and then gradually appears in neurons of more medial PA/LPO. Enkephalinergic fibers appear in $\mathrm{PP}$, presumably as neurons of PA/LPO develop their projections to PP. Although presently not demonstrated, it seems likely that the development of ELI in the mammalian basal ganglia is highly similar to that in the avian paleostriatal complex.

De Lanerolle et al. ('81) recently described the distribution of methionine-enkephalin in the chicken central nervous system. The De Lanerolle et al. results for the telencephalon differ greatly from those presented here in that the only ventral telencephalic structure reported by De Lanerolle et al. ('81) to contain appreciable amounts of enkephalin is the structure termed nucleus accumbens in the present report. No enkephalinergic neurons were observed in LPO-PA and no enkephalinergic fibers were seen in PP by De Lanerolle et al. ('81). The authors suggested 
that their observations might have their basis in a true phylogenetic difference in enkephalin distribution. This result and conclusion are inconsistent with the present immunohistochemical data in chickens and with the work of Bayon et al. ('80), who have reported that both a leucineenkephalin-like and a methionine-enkephalin-like materal are present in the pigeon paleostriatal complex. Crossblocking experiments in the present study indicate that several of the antisera used are highly specific for enkephalin peptides. For example, the ala-ala-ala-methionine ${ }^{5}$-enkephalin antiserum was highly specific for methionine-enkephalin and did not discernibly recognize Dynorphin A (1-8). We thus believe that the staining patterns reported here reflect the distribution of enkephalinergic peptides (similar or identical to leucine-enkephalin, methionine-enkephalin, BAM-22P, and Peptide E) in the avian telencephalon. The source of the disparity between our results and those of De Lanerolle et al. ('81) may be that the antisera used in their studies were of a different specificity and affinity than the antisera used in this study. Alternatively, the disparity between our study and that of De Lanerolle et al. ('81) may be based in differences in tissue fixation procedures. We have found that fixation with $4 \%$ paraformaldehyde alone is inadequate for optimal preservation of enkephalin antigenicity in avian nervous tissue. We obtained our optimal staining with the antisera used in the present study using sodium periodate and lysine with $4 \%$ paraformaldehyde, as described, and by limiting the length of postperfusion immersion fixation time.

\section{Implications}

Before the similarities between the mammalian basal ganglia and the avian paleostriatal complex were recognized, it was commonly believed that the bulk of the avian telencephalon consisted of nuclei of the basal ganglia. As part of this older point of view, it was also thought that the avian telencephalon lacked any structures homologous to the mammalian neocortex. In this context it is important to note that the relative paucity of enkephalinlike immunoreactivity in the mammalian neocortex distinguishes the neocortex from the ventral telencephalon, which is rich in enkephalinlike immunoreactivity. The LMD is the border between the avian basal ganglia and structures comparable to the mammalian neocortex (hyperstriatum, ectostriatum, and neostriatum) (Karten, '69; Nauta and Karten, '70; Karten and Dubbeldam, '73). We interpret the relative paucity of enkephalinlike immunoreactivity dorsal to LMD in birds and the similar relative scarcity of enkephalinlike immunoreactivity in the mammalian cortex, combined with the similar distributions of enkephalinlike immunoreactivity within the ventrolateral telencephalon, to be strong evidence that the avian telencephalon and the mammalian telencephalon share a common ancestry with respect to some of the major features of telencephalic organization. The distribution of enkephalinlike immunoreactivity within the paleostriatal complex of reptiles (including turtles, snakes, lizards, and caiman) is remarkably similar to that observed in the mammalian basal ganglia and to that described here for the avian paleostriatal complex (Naik et al., '81; Reiner, '83, unpub. obs.; Brauth, '84). Thus, the similar patterns of enkephalin distribution in the mammalian basal ganglia and avian paleostriatal complex may reflect the inheritance of these traits from the reptilian common ancestor.

Although the similarities in the distribution of enkephalinlike immunoreactivity in the ventrolateral telencephalic wall of mammals and birds are striking, an exact one-toone equivalence for all mammalian and avian nuclei in the basal telencephalon was not observed. For example, INP, the proposed equivalent of the internal segment of the globus pallidus (Karten and Dubbeldam, '73), is devoid of enkephalinlike immunoreactivity, unlike its proposed mammalian counterpart (Haber and Elde,'81; Wamsley et al., '80). Reiner et al. ('83) have recently noted that INP is also not similar to the internal segment of the mammalian globus pallidus in terms of the distribution of substance $P$. Further, Kitt and Brauth ('81) have noted that INP (unlike PP) does not receive input from overlying PA-LPO and does not give rise to any of the pallidal projections of the avian paleostriatal complex. Thus, INP does not appear comparable to the internal segment of the mammalian globus pallidus. Whether INP is a structure unique to the avian brain is uncertain. It is conceivable that INP represents a group of cells that in mammals are dispersed within the globus pallidus and whose lack of enkephalin-positive terminals is masked by the surrounding stained fibers. The existence of differences in the patterns of enkephalinlike immunoreactivity between mammalian and avian basal telencephala is not surprising, however, since birds and mammals are distinct vertebrate groups whose brains can be readily distinguished grossly. Nonetheless, the overall similarity in the distribution of enkephalinlike immunoreactivity in these two classes of vertebrates, together with other anatomical and biochemical data, argues that birds and mammals have inherited many of the basic histochemical and anatomical features of their basal ganglia from a common reptilian ancestor. Whether these basic features of the basal ganglia first appeared in reptiles or appeared in some vertebrate group that arose prior to reptiles is unclear. The present results suggest, in conjunction with the findings of others summarized above, that the evolution of the amniote telencephalon, at least with respect to the basal ganglia, has been much more conservative than once believed.

\section{ACKNOWLEDGMENTS}

Special thanks are in order to Dr. J.T. Erichsen for suggestions on the manuscript and to Nancy Shaw and Sharon Kumpuris for typing portions of this manuscript. This research was supported by NS 19620 (A.R.) and NS 12078 (H.J.K.).

\section{LITERATURE CITED}

Ariens-Kappers, C.U., G.C. Huber, and E.C. Crosby (1936) The Comparative Anatomy of the Nervous System, Including Man. New York: MacMillan.

Bayon, A., L. Koda, E. Battenberg, R. Azad, and F.E. Bloom (1980) Regional distribution of endorphin, met-enkephalin and leu-enkephalin in the pigeon brain. Neurosci. Lett. 16:75-80.

Bertler, A., B. Falk, C.G. Gottfried, L. Ljunggren, and E. Rosengren (1964) Some observations on adrenergic connections between mesencephalon and cerebral hemispheres. Actcl Pharmacol. 21:383-289.

Blähser, S., and M.P. Dubois (1980) Immunocytochemical demonstration of met-enkephalin in the central nervous system of the domestic fowl. Cell Tissue Res. 213:53-68.

Brauth, S.E. (1964) Enkephalin-like immunoreactivity within the telencephalon of the reptile Caiman crocodilus. Neuroscience 11:345-358.

Brauth, S.E., J.L. Ferguson, and C.A. Kitt (1978) Prosencephalic pathways related to the paleostriatum of the pigeon, Columba livia. Brain Res. 
147:205-221.

Carpenter, M.B. (1976) Anatomical organization of the corpus striatum and related nuclei. In M.P. Yahr (ed): The Basal Ganglia. New York: Raven Press, pp. 1-36.

Comb, J., P.H. Seeburg, J. Adelman, L. Eiden, and E. Herbert (1982) Pri mary structure of the human Met- and Leu-enkephalin precursor and its mRNA. Nature 295:663-666.

Coons, A.H. (1958) General Cytochemical Methods. New York: Academic Press.

Cuello, A.C., and I. Kanazawa (1978) The distribution of substance P im munoreactive fibers in the rat central nervous system. J. Comp. Neurol. 178: $129-156$.

De Lanerolle, N.C., R.P. Elde, S.B. Sparber, and M. Frick (1981) Distribution of methionine-enkephalin immunoreactivity in the chick brain: An immunohistochemical study. J. Comp. Neurol. 199:513-533.

Del Fiacco, M., G. Paxinos, and A.C. Cuello (1980) Neostriatal enkephalin immunoreactive neurons project to the globus pallidus. Brain Res. 231:117.

Dube, L., and A. Parent (1981) The monoamine-containing neurons in the avian brain. I. A study of the brain stem of the chicken (Gallus domesticus) by means of fluorescence and acetycholinesterase histochemistry. J. Comp. Neurol. 196:695-708.

Fuxe, K. (1965) Evidence for the existence of monoamine neurons in the central nervous system. IV. Distribution of monoamine nerve terminals in the central nervous system. Acta Physiol. Scand. 247/Suppl. 64J:3985.

Gall, C., N. Brecha, H.J. Karten, and K.-J. Chang (1981) Localization of enkephalin-like immunoreactivity to identified axonal and neuronal populations of the rat hippocampus. J. Comp. Neurol. 198:335-350.

Haber, S., and R. Elde (1981) Correlation between met-enkephalin and substance $\mathrm{P}$ immunoreactivity in the primate globus pallidus. Neuroscience 6:1291-1297.

Hamberger, V., and H.L. Hamilton (1951) A series of normal stages in the development of the chicken embryo. J. Morphol. 88:49-92.

Heimer, L. (1978) The olfactory cortex and the ventral striatum. In K.E. Livingston and $O$. Hornykiewicz (eds): Limbic Mechanisms: The Continuing Evolution of the Limbic System Concept. New York: Plenum Press, pp. 95-187.

Herrick, C.J. (1948) The Brain of the Tiger Salamander. Chicago: University of Chicago Press.

Jacobowitz, D.M., and M. Palkovits (1974) Topographic atlas of catecholamine and acetylcholinesterease-containing neurons in the rat brain. I Forebrain (telencephalon, diencephalon). J. Comp. Neurol. 157:13-28.

Jessell, T.M., P.C. Emson, G. Paxinos, and A.C. Cuello (1978) Topographic projections of substance $P$ and GABA pathways in the striato-pallidonigral system: A biochemical and immunohistochemical study. Brain Res. 152:487-498.

Juorio, A.V., and M. Vogt (1967) Monoamines and their metabolites in the avian brain. J. Physiol. (Lond.) 189:489-518.

Källén, B. (1951) Embryological studies on the nuclei and their homologization in the vertebrate forebrain. Kungl. Fysiograf. Sallskapets. Handl. N.F. 62, N.5, pp. $1-36$.

Källén, B. (1962) Embryogenesis of brain nuclei in the chick telencephalon. Ergebn. Anat. Entw. Gesch. 36:62-82.

Kanazawa, I., and T.M. Jessell (1976) Postmortem changes and the regional distribution of substance $P$ in the rat and mouse nervous system. Brain Res. 117:362-367.

Karten, H.J. (1969) The organization of the avian telencephalon and some speculations on the phylogeny of the amniote telencephalon. Ann. NY Acad. Sci. 167:164-168.

Karten, H.J., and J.L. Dubbeldam (1973) The organization and projections of the paleostriatal complex in the pigeon (Columbia livia). J. Comp. Neurol. 148:61-90.

Karten, H.J., and W. Hodos (1967) A Stereotaxic Atlas of the Brain of the Pigeon (Columba livia). Baltimore: Johns Hopkins Press.

Khachaturian, H., M.E. Lewis, V. Hollt, and S.J. Watson (1983a) Telencephalic enkephalinergic systems in the rat brain. J. Neurosci. 3:844-855.

Khachaturian, H., S.J. Watson, M.E. Lewis, D. Coy, A. Goldstein, and H. Akil (1983b) Dynorphin immunoreactivity in the rat central nervous system. Peptides 3:941-954.

Kitt, C.A., and S.E. Brauth (1981) Projections of the paleostriatum upon the midbrain tegmentum in the pigeon. Neuroscience 6:1551-1566.
Kuhar, M.J., C.B. Pert, and S.H. Snyder (1973) Regional distribution of opiate receptor binding in monkey and human brain. Nature 245:447450.

Ljungdahl, A., T. Hokfelt, and G. Nilsson (1978) Distribution of substance P-like immunoreactivity in the central nervous system of the rat. I. Cell bodies and nerve terminals. Neuroscience 3:861-944.

McLean, I.W., and P.K. Nakane (1974) Periodate-lysine-paraformaldehyde fixative. A new fixative for immunoelectron microscopy. J. Histochem. Cytochem. 22:1077-1083

Miller, R.J., K.J. Chang, B. Cooper, and P. Cuatrecasas (1978) Radioimmunoassay and characterization of enkephalins in rat tissue. J. Biol. Chem. 253:531-538.

Naik, D.R., M. Sar, and W.E. Stumpf (1981) Immunohistochemical localization of enkephalin in the central nervous system and pituitary of the lizard, Anolis carolinensis. J. Comp. Neurol. 198:583-601.

Nauta, W.J.H., and W. Mehler (1966) Projection of the lentiform nucleus in the monkey. Brain Res. 1:1-42.

Nauta, W.J.H., and H.J. Karten (1970) A general profile of the vertebrate brain with sidelights on the ancestry of the cerebral cortex. In F.O. Schmitt (ed): The Neurosciences. Second Study Program. New York: Rockefeller University Press, pp. 7-26.

Nauta, H.J.W. (1979) Projections of the pallidal complex: An autoradiographic study in the cat. Neuroscience 4:1853-1873.

Newman, R., and S.S. Winans (1980a) An experimental study of the ventral striatum of the golden hamster. I. Neuronal connections of the nucleus accumbens. J. Comp. Neurol. 191:167-192.

Newman, R., and S.S. Winans (1980b) An experimental study of the striatum of the golden hamster. II. The neuronal connections of the olfactory tubercle. J. Comp. Neurol. 191:193-212.

Nicoll, R.A., B.E. Alger, and C.E. Jahr (1980) Peptides as putative excitatory neurotransmitters: carnosine, enkephalin, substance P and TRH. Proc R. Soc. Lond. 210:133-149.

Noda, M., Y. Furitani, H. Takahashi, M. Totosato, T. Hirose, S. Inayama, S. Nakanishi, and S. Numa (1982) Cloning and sequence analysis of cDNA for bovine adrenal pre-proenkephalin. Nature 295:202-206.

Palkovits, M., E.A. Mroz, M.J. Brownstein, and S.E. Leeman (1978) De scending substance P-containing pathway: A component of the ansa lenticularis. Brain Res. 156:124-128.

Parent, A., and A. Olivier (1970) Comparative histochemical study of the corpus striatum. J. Hirnforsch. 12:73-81.

Parent, A. (1973a) Distribution of monoamine-containing nerve terminals in the brain of the painted turtle, Chrysemys picta. J. Comp. Neurol. 148:153-166.

Parent, A. (1973b) Demonstration of a catecholaminergic pathway from the midbrain to the strioamygdaloid complex in the turtle (Chrysemys picta). J. Anat. 114:379-387.

Pert, C.B., D. Aposhian, and S.H. Snyder (1974) Phylogenetic distribution of opiate receptor binding. Brain Res. 75:356-361.

Pickel, V.M., K.K. Sumal, S.C. Beckley, R.J. Miller, and D.J. Reis (1981) Immunocytochemical localization of enkephalin in the neostriatum of rat brain: A light and electron microscopic study. J. Comp. Neurol 189:721-741.

Reiner, A. (1983) Comparative studies of opioid peptides: Enkephalin distribution in turtle central nervous system. Soc. Neurosci. Abstr. 9:439

Reiner, A., N.C. Brecha, and H.J. Karten (1982a) Basal ganglia pathways to the tectum: The afferent and efferent connections of the lateral spiriform nucleus of pigeons. J. Comp. Neurol. 208:16-36.

Reiner, A., H.J. Karten, and N.C. Brecha (1982b) Enkephalin-mediated basal ganglia influences over the optic tectum: Immunohistochemistry of the tectum and the lateral sipriform nucleus in pigeon. J. Cornp. Neurol. 208:37-53.

Reiner, A., H.J. Karten, and A.R. Solina (1983) Substance P: Localization within paleostrioatal-tegmental pathways in pigeons. Neuroscience 9:6185.

Sar, M.W., W. Stumpf, R.J. Miller, K.-J. Chang, and P. Cuatrecasas (1978) Immunohistochemical localization of enkephalin in the rat brain and spinal cord. J. Comp. Neurol. 182:17-38.

Sidman, R.L., and J.B. Angevine, Jr. (1962) Autoradiographic analysis of time of origin of nuclear versus cortical components of mouse telencephalon. Anat. Rec. 142:326-327.

Simantov, R., M.J. Kuhar, G.W. Pasternak, and S.H. Snyder (1976a) The regional distribution of a morphine-like factor "enkephalin" in the monkey brain. Brain Res. 106:189-197. 
Simantov, R., R. Goodman, D. Aposhian, and S.H. Snyder (1976b) Phylogentic distribution of a morphine-like peptide "enkephalin." Brain Res. 111:204-211.

Simantov, R., M. Kuhar, G. Uhl, and S. Snyder (1977) Opioid peptide enkephalin: Immunohistochemical mapping in the rat central nervous system. Proc. Natl Acad. Sci. U.S.A. 74:2167-2171.

Sternberger, L.A. (1977) Immunohistochemistry. Second Edition. New York: John Wiley and Sons.

Switzer, R.C., and J.M. Hill (1979) Globus pallidus component in olfactory turbercle: Evidence based on iron distribution. Soc. Neurosci. Abstr. $5: 79$.

ten Donkelaar, H.J., and P.J.W. Dederen (1979) Neurogenesis in the basal forebrain of the Chinese hamster (Cricetulus griseus). I. Time of neuron origin. Anat. Embryol. 156:331-348.

Tsai, H.M., B.B. Garber, and L.M.H. Larramendi (1981a) ${ }^{3}$ H-Thymidine autoradiographic analysis of telencephalic histogenesis in the chick embryo. 1. Neuronal birthdates of telencephalic compartments in situ. J. Comp. Neurol. 198:275-292.

Tsai, H.M., B.B. Garber, and L.M.H. Laramendi (1981b) ${ }^{3}$ H-Thymidine autoradiographic analysis of telencephalic histogenesis in the chick embryo. II. Dynamics of neuronal migration, displacement and aggregation. J. Comp. Neurol. 198:293-306.

Van Tienhoven, A., and L.P. Juhasz (1962) The chicken telencephalon, diencephalon and mesencephalon in stereotaxic coordinates. J. Comp. Neurol. 118:185-197.

Vincent, S., T. Hokfelt, I. Christensson, and L. Terenius (1982) Immunohistochemical evidence for a dynorphin immunoreactive striatonigral pathway. Eur. J. Pharmacol. 85:251-252.

Wamsley, J.K., W.S. Young III, and M.J. Kuhar (1980) Immunohistochemical localization of enkephalin in rat forebrain. Brain Res. 190:153-174.

Watson, S.J., H. Khachaturian, H. Akil, D. Coy, and A. Goldstein (1982) Comparison of the distribution of dynorphin systems and enkephalin systems in brain. Science 218:1134-1136.

Weber, E., C.J. Evans, and J.D. Barchas (1982) Predominance of the aminoterminal octapeptide fragment of dynorphin in rat brain regions. Nature 299:77-79.

Youngren, O.M., and R.E. Philips (1978) A stereotaxic atlas of the brain of the three-day-old domestic chick. J. Comp. Neurol. 181:567-600. 